\title{
Intraday Behavior of Stock Prices and Trades around Insider Trading
}

\author{
A. Can Inci, Biao Lu, and H. Nejat Seyhun*
}

\begin{abstract}
Our evidence indicates that insiders' trades provide significant new information to market participants and they are incorporated more fully in stock prices as compared to noninsiders' trades. We find that market professionals do not front-run insiders' trades. Both insiders' purchases and sales result in significant contemporaneous and subsequent price impact, while sales by large shareholders result in a contemporaneous stock price decline that is subsequently reversed. The arrival of insider purchases reverse the prevailing negative order imbalances from third party trades and lead to piggy-backing by market professionals resulting in subsequent market purchase orders as well as stock price increases.
\end{abstract}

How market participants react to the presence of informed traders has important implications for the determination of security prices and bid-ask quotes. In some models of price formation, security prices fully and immediately reveal the information possessed by informed traders (Grossman, 1976), while in other models, security prices react gradually through subsequent informed buying and selling activity (Bagehot, 1971; Grossman and Stiglitz, 1980; Glosten and Milgrom, 1985; Kyle, 1985; Glosten, 1989; Foster and Viswanathan, 1994). If the presence of informed traders is not discovered directly, then market makers need to protect themselves from informed traders by setting a sufficiently high bid-ask spread. Market participants also attempt to infer the presence of informed traders indirectly from trade size, firm size, urgency of trade, time of day, and price variability (Kraus and Stoll, 1972; French and Roll, 1986; Holthausen, Leftwich, and Mayers, 1987, 1990; Admati and Pfleiderer, 1988; Barclay, Litzenberger, and Warner, 1990; Hasbrouck, 1991a, 1991b; Barclay and Warner, 1993; Keim and Madhavan, 1996; Koski and Michaely, 2000; Chakravarty, 2001).

In this paper, we document the intraday reaction of market professionals to the presence of corporate insiders. Our evidence indicates large initial stock price adjustments on insiders, followed by persistent piggy-backing of insiders' trades and continued price reactions for the rest

We are grateful for the helpful comments and suggestions by Bill Christie (editor), an anonymous referee, Sugato Bhattacharyya, Sreedhar Bharath, Radha Gopalan, Jennifer Koski, M.P. Narayanan, Paige Ouimet, Paolo Pasquariello, Uday Rajan, Noah Stoffman, Seha Tinic, Ingrid Werner, and seminar participants at Bilkent University, Florida State University, Marmara University, Koc University, the University of Michigan, the Western Finance Association Meetings, European Financial Management Meetings, FMA Europe Meetings, and the US Securities and Exchange Commission. The usual disclaimer applies.

${ }^{*}$ A. Can Inci is an Associate Professor of Finance at Bryant University in Smithfield, RI. Biao Lu is a Portfolio Manager and Director at Tudor Investment Corporation in Greenwich, CT. H. Nejat Seyhun is the Jerome B. and Eilene M. York Professor of Business Administration and Professor of Finance at the University of Michigan in Ann Arbor, MI. 
of the day. ${ }^{1}$ Both of these adjustments reduce market professionals' losses to informed traders. Our evidence further suggests that stock prices incorporate insiders' information more quickly and more fully relative to similar trades from noninsiders.

Using a large intraday transactions database, we identify insiders' trades to the hour, minute, and second by matching them against all intraday trades. Some previous studies have also examined intraday stock price reaction to insider trading. Garfinkel and Nimalendran (2003) document a differential bid-ask spread adjustment among insider and noninsider trades between New York Stock Exchange (NYSE) and National Association of Securities Dealers Automated Quotation system (NASDAQ) stocks. Meulbroek (1992) analyzes stock price reaction in 320 illegal insider trading cases. Similarly, using small samples of illegal insider trading cases, Cornell and Sirri (1992), Chakravarty and McConnell (1997, 1999), and Fishe and Robe (2004) analyze the relationship between illegal insider trading volume and stock prices, bid-ask spreads, and market depth. There is also abundant literature regarding insider trading using daily or monthly returns. Most insider trading studies find that insiders can predict 6- to 36-month future returns to their firms' stocks (Jaffe, 1974; Finnerty, 1976; Seyhun, 1986, 1998; Rozeff and Zaman, 1988; Lin and Howe, 1990; Lakonishok and Lee, 2001; Garfinkel, Kahle, and Shastri, 2007). The only notable exception is Eckbo and Smith (1998) who find that an aggregate insider portfolio of stocks listed on the Oslo Stock Exchange did not outperform managed funds. Chung and Charoenwong (1998) also examine the reaction of bid-ask spread to insider trading. On the aggregate level, Seyhun $(1988,1998)$ and Lakonishok and Lee (2001) determine that aggregate insider trading activity can also predict future stock market movements. Clearly, insiders have information advantages at both the firm level and the market level. Other authors focus on trader identity and have studied the price impact of specialists, SuperDOT traders, and institutional traders (Hasbrouck and Sofianos, 1993; Chan and Lakonishok, 1993, 1995; Harris and Hasbrouck, 1996).

Our insider trading database contains over 177,000 observations. On a trade-by-trade basis, we find that the arrival of an insider purchase causes a large and significant initial price impact. Stock prices continue to rise after insider purchases, resulting in a significant subsequent price impact as well. The arrival of insider purchases also changes the order imbalance. Prior to insider purchases, prices have been decreasing throughout the day and trades are characterized by market sell orders. Following insider purchases, prices rise for the rest of the day and trades are characterized by market buy orders. The intensity of trading activity also increases following the arrival of insider purchases. Insider purchases are found to be executed almost at the bottom price over a 61day window and right at the moment when the previous downward price trend is reversed. The significance of the detected initial and subsequent price impacts remains intact after we control for trade size, bid-ask bounce, firm size, and the prior price trend using a matched noninsider trade sample. We further examine the effects of bid-ask bounce by using returns based on quoted ask prices instead of transaction prices (see Section II.G.1). The detected price impacts again remain intact (our use of the quoted bid and ask quotes follows that in Koski and Michaely, 2000).

The significant price impacts and the reversals of price trend and order imbalances suggest that market professionals (brokers and market makers) take into account the presence of registered

\footnotetext{
${ }^{1}$ The episode involving Martha Stewart's December 27, 2001 sales of ImClone Systems stock provides a well-publicized example of piggy-back trading. After ImClone founder and CEO, Dr. Sam Waksal, was tipped about an impending rejection of the Erbitux application, he tipped his daughter to sell her stock and tried to sell 79,000 of his own shares (worth about \$5 million) as well. Peter Bacanovic, broker for both Dr. Waksal and Ms. Stewart at Merrill Lynch, alerted Ms. Stewart about the attempted sale by Dr. Waksal. Martha Stewart then sold 3,928 shares of ImClone stock for a total of $\$ 228,000$. Thus, even an unsuccessful sale attempt by the CEO brought about piggy-back sales by Martha Stewart. In this case, Mr. Bacanovic violated Merrill Lynch's confidentiality policy by disclosing Dr. Waksal's and his daughter's actions to Ms. Stewart. Both Ms. Stewart and Mr. Bacanovic were convicted of four counts of perjury and obstruction of justice on March 5, 2004. However, Ms. Stewart was not charged with insider trading for selling ImClone stock.
} 
corporate insiders at the time of insider purchases. One possible source of this information is the account registration statements where the insiders disclose their special relationship to their firm. Our evidence also suggests that market professionals use their knowledge about insider purchases to execute additional purchases either for themselves or for their favored clients.

The price impact of insider purchases has interesting correlations to various trade attributes that have been candidates for proxies of informed trading. First, consistent with Easley and O'Hara (1987), the full-day price impact is positive and uniform in trade size. Insiders do trade larger volumes when they have more precise information. Second, the firm size variable is important. Insider purchases in smaller firms have larger initial and subsequent price impacts than those in larger firms. Third, price impact of insider trading is also greater to the extent that it provides a surprise element in contradiction to other market trends. An insider purchase has a greater price impact in a seller-dominated environment than in a buyer-dominated environment. It appears that market professionals look to insider trading for potential reversals of long-term price trends. Fourth, a sizable portion of insider purchases are executed through limit orders, which, by our definition, are insider purchases with prices less than the average of the prevailing bid and ask prices. We find that insiders also make much greater profits from limit orders than they do from market orders. Our evidence cautions against characterizing market orders as information motivated trades and limit orders as liquidity motivated trades. Finally, when comparing the price reactions of insiders' and matching noninsiders' trades, we find that quote revisions in reaction to insider trades are larger and longer lasting.

We observe that insider sales also cause a significant and negative contemporaneous price impact regardless of trade size. Furthermore, the price impact for top executives' and officers' sales is not reversed during the remainder of the day. However, for large shareholders, the selling pressure is quickly reversed during the following trades. The overall sales sample is dominated by large shareholders reducing the information content of insiders' sales. The asymmetry in the full-day effects of insider purchases and sales does not appear to be caused by different trading behavior of insiders. Insiders still act contrarian as the prices have been increasing throughout the day prior to insider sales. This finding is again different from the findings regarding institutional traders, who tend to sell after prices have been declining. It is more plausible that other market participants regard insider sales as less telling and less informed than insider purchases. Since corporate insiders are often endowed with large numbers of shares of stock and stock options, their sales are more likely to be driven by liquidity or portfolio rebalancing needs and their purchases are more likely to be information motivated.

The rest of the paper is organized as follows. In Section I, we describe the construction of our sample of insider trades. We also provide a preliminary analysis of these trades. In Section II, we analyze the intraday behavior of stock prices around insider purchases and sales. We also analyze the relationship between price impacts of insider trades and various potential proxies for informed trading including order imbalance measures, speed of information incorporation, and price discovery analyses. In Section III, we proffer our conclusions. A discussion of our matching procedures and potential biases arising from matching are found in the Appendix.

\section{Data Construction and Characteristics of Insider Trades}

\section{A. The Data}

According to the Securities and Exchange Act of 1934, the term "corporate insiders" refers to corporate officers, directors, and large shareholders who own more than $10 \%$ of the firm's stock. If insiders buy or sell their firm's stock, they are mandated to file with the Securities and Exchange 
Commission (SEC) within the first 10 days of the next month following their transactions. ${ }^{2}$ The SEC filing of each insider transaction includes information regarding the date, price, size, identity of the insider, the insider's relationship to the firm, and whether it is a purchase or sale. The SEC data are also the original source for several commercial vendors, such as CDA/Investnet, that provide data and analysis on insider trading.

To study the market microstructure effects of insider trading, however, one needs intraday information on the insider trades. Our first initiative is to identify the reported insider transactions from background trades on the same stocks recorded in the transaction database. This results in an intraday sample that has the exact transaction time for each identified insider trade in addition to other information available in the SEC data.

We include only the open market purchases and sales by corporate officers, directors, and large shareholders on the NYSE, the American Stock Exchange (AMEX), and the NASDAQ stocks for a 15-year period January 1, 1988-December 31, 2002. The background trading on the stocks in the insider trade data are taken from the Institute for the Study of Security Markets (ISSM) transaction database for the period January 1988-December 1992 and the Trade and Quote (TAQ) transaction database for the period January 1993-December 2002. Both databases provide a detailed time stamped chronology of each TAQ for NYSE/AMEX/NASDAQ stocks over the same period. The trade data include the transaction price, volume, time of execution, and originating exchange of the trade. The quote data include the ask price, bid price, depth on both sides, posting time of the quote, and originating exchange of the quote. Trade size and quoted depths are measured in round lots of 100 shares and times of trade executions and quote postings are to the nearest second. The official tick size has evolved considerably during the sample period. The official tick size is one-eighth for all NYSE/AMEX/NASDAQ stocks during the 1988-1992 period covered by the ISSM database as well as the period until June 1997. In June 1997, the tick size is reduced to one-sixteenth by the exchanges. Finally, the decimalization of stock price quotations takes place in several phases from August 28, 2000 to April 9, 2001. We consider all these changes while identifying insider trades. ${ }^{3}$ The ISSM and TAQ databases also contain some trade prices quoted to one-sixteenth over 1988-1997. While they are quite uncommon, we treated these price quotes as valid prices.

Our primary method of identifying the insider trades from the background trading on the stocks is to match the price and size of each reported insider transaction with those trades recorded in the ISSM and TAQ databases. The reported insider transaction prices are rounded to the cent. While most of these reported prices are rounded up, some are rounded down. Therefore, we allow for a maximum of a half cent difference in either direction when matching the prices. This price volume matching is also used by Cornell and Sirri (1992) to identify a small sample of illegal insider purchases of Campbell Taggart stock in 1982.

We start by checking whether the reported insider trade has a matching ticker symbol in the ISSM or TAQ databases for identification purposes. Given a valid ticker symbol, the second filter ensures that the firm has a valid market price. If the insider trade passes these two filters, then

\footnotetext{
${ }^{2}$ After August 29, 2002, insiders are required to report their trades within two business days. Insiders may also voluntarily file "proposed sales" with the SEC in advance if they plan to sell shares. However, they can choose to sell shares at any time within the next six months after this pretrade filing. If they plan to purchase shares, they are not required to do any pretrade filings and they typically do not file with the SEC before the purchases.

${ }^{3}$ Decimalization phases for NYSE stocks were on August 28, 2000 (7 stocks), September 25, 2000 ( 57 stocks), December 4, 2000 (94 stocks), and January 29, 2001 (all stocks). NASDAQ transition phases were on March 12 (14 stocks), March 25 (197 stocks), and April 9 (all stocks), all in 2001. For AMEX, August 28, 2000 and September 25, 2000 phases were followed by the third and final phase on April 9, 2001. We follow each stock's decimalization date while matching the insider trade.
} 
our third filter attempts to identify a valid trade size. ${ }^{4}$ The fourth filter eliminates multiple insider trades that take place on the same date with the same size and price at the same firm. ${ }^{5}$ Our fifth filter requires a unique price volume match to the insider trade so that it can be included in the final intraday sample. The sixth filter requires that each uniquely matched trade be executed at the same exchange on which the stock is listed. Finally, the seventh filter requires that the uniquely matched trade take place during the regular trading hours of 9:30 a.m.-4 p.m. to extract overnight trading issues.

After running through the seven filters, our intraday sample has 177,745 insider trades from 1988 to 2002 , with 65,845 insider purchases and 111,900 insider sales, respectively. The annual number of insider trades in the intraday sample ranges from 6,732 in 1991 to 19,194 in 2001.

\section{B. Sample Characteristics}

In Table I, we report the trade size distribution, the firm size distribution of the intraday sample, and prices of the insider trades in relation to their average prevailing bid and ask prices. Lee and Ready (1991) find that bid-ask quotes may be recorded ahead of the trades that triggered them. They propose to use the most recent quote that is recorded at least five seconds prior to time of the trade as the prevailing bid-ask quote. We adopt this rule, which is also widely used in the literature.

Panel A demonstrates that there are significantly smaller and medium size trades than there are large ones. For example, 20,995 trades are fewer than 500 shares, 18,811 trades are from 500 to 1,000 shares, 102,212 trades are from 1,000 to 10,000 shares, but only 4,270 trades are more than 50,000 shares. The insider trades in our intraday sample are significantly smaller than typical institutional trades, and more so for purchases than for sales (Chan and Lakonishok, 1993).

We classify firm sizes of stocks in the intraday sample on a scale of 1-10, where 1 represents the $10 \%$ smallest stock and 10 represents the $10 \%$ largest stocks in terms of market capitalizations in each year during 1988-2002. This size classification is based on the deciles of equity market values of all the NYSE, AMEX, and NASDAQ stocks at the beginning of the year. Panel B reports statistics based on four firm size groups with market capitalization deciles of 1-3, 4-6, 7-8, and 9-10, respectively. In terms of the number of trades, there are more insider purchases than sales in small firms (Size Deciles 1-3) and there are more sales than purchases in large firms (Size Deciles 4-6, 7-8, and 9-10).

As indicated in Panel C, among all the insider purchases, $65.9 \%, 5.3 \%$, and $28.8 \%$ of those transactions are executed at prices higher than, equal to, or less than the average prevailing bid and ask prices. Among insider sales, $69.8 \%, 5.4 \%$, and $24.8 \%$ of those trades are executed at prices less than, equal to, or higher than the average of the prevailing bid and ask prices. We classify a purchase as a market order if its trade price is at the midpoint of the bid-ask price or above. Otherwise, it is defined as a limit order. We identify a sale as a market order if its trade price is at the midpoint of the bid-ask price or below. Otherwise, it is referred to as a limit order.

\footnotetext{
${ }^{4}$ While a majority of the reported insider trades are in hundreds of shares, a small fraction of them are not. Since the trade sizes in the ISSM and TAQ databases are always rounded to hundreds of shares, we allow the same rounding when matching the volumes for this small fraction of insider trades. For example, on June 6, 1990, a vice president at the Dayton Hudson Corporation sold 6,074 shares at the reported price of \$72.63. Based on our matching criterion, this insider trade will be matched to the ISSM trade with a price of $\$ 72.625$ and volume of 6,100 shares.

${ }^{5}$ We check the sensitivity of our results to this filter by including all days with multiple trades. 24,900 such trades, of which 11,486 are purchases and 13,414 sales, are added to the final sample without this filter. Neither the trade-by-trade abnormal return results before and after the insider sale/purchase nor the cumulative abnormal average stock return patterns around the insider sale/purchase vary other than a negligible loss of significance without the filter. These results are available upon request.
} 


\section{Table I. Summary Statistics on Matched Insider Trades}

This table presents the trade size distribution, the firm size distribution of the matched insider trades, and the correlations of insider trade prices to the average prevailing bid-ask prices. The firm size classification for each year from 1988 to 2002 is based on deciles of equity market values of all New York Stock Exchange, American Stock Exchange, and NASDAQ stocks at the beginning of the year. Decile 1 represents the $10 \%$ smallest firms and Decile 10 represents the $10 \%$ largest firms. The prevailing bid-ask quote for each matched insider trade is the most recent quote that is recorded at least five seconds prior to time of the trade, according to Lee and Ready (1991).

Panel A. Trade Size Distribution

\begin{tabular}{lrrrrrr}
\hline \hline $\begin{array}{l}\text { Number } \\
\text { of Shares }\end{array}$ & {$[\mathbf{1 0 0 , 5 0 0 )}$} & {$[\mathbf{5 0 0 , 1 , 0 0 0 )}$} & {$[\mathbf{1 , 0 0 0 , 1 0 , 0 0 0 )}$} & {$[\mathbf{1 0 , 0 0 0 , 5 0 , 0 0 0 )}$} & $\mathbf{2} \mathbf{5 0 , 0 0 0}$ & Total \\
\hline Purchases & 13,014 & 9,600 & 35,966 & 6,432 & 833 & 65,845 \\
Sales & 7,981 & 9,211 & 66,246 & 25,025 & 3,437 & 111,900 \\
Total & 20,995 & 18,811 & 102,212 & 31,457 & 4,270 & 177,745 \\
\hline \hline
\end{tabular}

Panel B. Firm Size Distribution

\begin{tabular}{lccccc}
\hline \hline Size Decile & $\mathbf{1 - 3}$ & $\mathbf{4 - 6}$ & $\mathbf{7 - 8}$ & $\mathbf{9 - 1 0}$ & Total \\
\hline Purchases & 13,792 & 25,199 & 15,849 & 11,005 & 65,845 \\
Sales & 10,023 & 31,565 & 33,026 & 37,286 & 111,900 \\
Total & 23,815 & 56,764 & 48,875 & 48,291 & 177,745 \\
\hline
\end{tabular}

Panel C. Insider Trade Price Relative to Average Bid-Ask Prices

\begin{tabular}{lcccr}
\hline \hline & $\begin{array}{c}\text { Price }>\text { Average } \\
\text { Bid-Ask }\end{array}$ & $\begin{array}{c}\text { Price }=\text { Average } \\
\text { Bid-Ask }\end{array}$ & $\begin{array}{c}\text { Price }<\text { Average } \\
\text { Bid-Ask }\end{array}$ & \multicolumn{1}{c}{ Total } \\
\hline Purchases & $43,408(65.9 \%)$ & $3,486(5.3 \%)$ & $18,951(28.8 \%)$ & $65,845(100 \%)$ \\
Sales & $27,778(24.8 \%)$ & $5,991(5.4 \%)$ & $78,131(69.8 \%)$ & $111,900(100 \%)$ \\
\hline \hline
\end{tabular}

We also experimented with two additional definitions of market and limit orders when the trade price was exactly equal to the midpoint of the bid and ask prices. From Table I, these trades constitute about $5 \%$ of the overall sample. First, we excluded all these trades. Alternatively, we included these trades as part of the limit orders. In either case, all our qualitative conclusions hold. It appears that corporate insiders often use limit orders. Since their private information is not likely to be revealed to the market soon, insiders are in no hurry to execute trades and would prefer to have better control over prices. These numbers also illustrate the importance of identifying the directions of insider trades. If we did not recognize the trade directions and instead used a classification scheme such as the quote test, at least $28.8 \%$ of insider purchases would be classified as seller initiated and at least $24.8 \%$ of insider sales would be classified as buyer initiated. ${ }^{6}$ This would result in a sample of buyer-initiated trades with insiders as buyers of some trades but sellers of other trades. This would be similarly true for a sample of seller-initiated trades. Lack of trade direction knowledge would make it very difficult to detect the true price impacts of insider trades.

\footnotetext{
${ }^{6} \mathrm{~A}$ quote test classifies a trade to be buyer or seller initiated if the trade price is higher or lower than its prevailing average bid-ask price. If the trade price is equal to the average bid-ask price, then further classifications are often used.
} 


\section{Stock Prices around Insider Trades}

\section{A. Preliminaries}

In this section, we investigate the following empirical questions: 1) Is there a price impact from insider trading immediately prior to, at the time of trade, or immediately thereafter? 2) Is there a price impact from insider trading by the end of the trading day? 3) How are price impacts related to various trade attributes? and 4) Do insiders place both market and limit orders to take advantage of their private information? The answers to the first three questions aid us in understanding whether the presence of insiders is discovered at the time of trade and how private information possessed by insiders is assimilated into prices through trading. The answer to the last question helps us to understand the behavior of informed traders.

We analyze these issues by examining the intraday behavior of stock prices around insider trades using trade-to-trade abnormal returns. We also conducted the analysis using unadjusted trade-to-trade raw returns. The results are essentially the same. The abnormal returns are raw returns adjusted for returns on a composite market index, which is used minute by minute over the sample period from January 1, 1988 to December 31, 2002. The index is provided by the Institute for Financial Markets and actually has an approximate frequency of four times per minute. The average index value for that minute is used to calculate the corresponding abnormal return.

To fix notation, we denote each insider trade as Trade 0 . That is, we center the intraday sample at the insider trades. The trade prior to each insider trade is denoted as Trade -1 and the next trade after each insider trade is denoted as Trade 1. All the other trades prior to and following an insider trade are similarly indexed. The price of the $t$ th trade around the $i$ th insider trade is denoted as $P_{t, i}$. Corresponding to each $t$ th trade, $M_{t, i}$ refers to the level of the value-weighted market index at the same minute as that trade.

We now provide a preliminary look at the price impact of insider trading by plotting the cumulative trade-by-trade averages of abnormal returns, $C A A R_{t}$, for 60 trades before and after insiders' transactions separately for purchases and sales as shown in Figure 1. Prior to insiders' purchases, prices tend to drop. Immediately preceding insiders' purchases (the last three trades), prices seem to stabilize, giving no hint of the impending insiders' purchases. On insiders' purchases, prices rise significantly from the previous trade. This is the largest price change in the entire graph. Following insiders' purchases, prices continue to drift upward for the rest of the day.

A similar picture emerges around insiders' sales Prices tend to rise slightly prior to insiders' sales and decline directly after insiders' sales. In contrast to insiders' purchases, there is no downward drift following insiders' sales. Instead, prices tend to bounce back up and then stabilize.

Instead of examining stock price reaction on a trade-by-trade basis, we also examined stock price reactions for 10- and 30-second intervals. Once again, immediate stock price reaction to insiders' transactions is evident. Stock prices climb for the next trade after insiders' purchases even if that trade occurs within ten seconds.

Overall, our preliminary evidence suggests that insiders' trades are discovered at the time of the trade. This is likely to be due to the fact that insiders have to disclose their insider identity to the brokers at the time they open their accounts. Consequently, arrival of a trade from an insider account at that time has substantial price effects. Looking at prior price effects, in both purchases and sales, insiders seem to be leaning against the prevailing prior price drift. The arrival of insiders' trades results in substantial initial price effects, positive for purchases and negative for sales. Finally, long-term price effects of purchases and sales seem to diverge. For purchases, it appears that there is a continuing price impact, while for sales the majority of the price effect appears to be temporary and reversed following insiders' sales. Hence, upward drift following 
Figure 1. Trade-by-Trade Abnormal Stock Price Reactions around Insiders' Sales and Purchases (Trade 0)

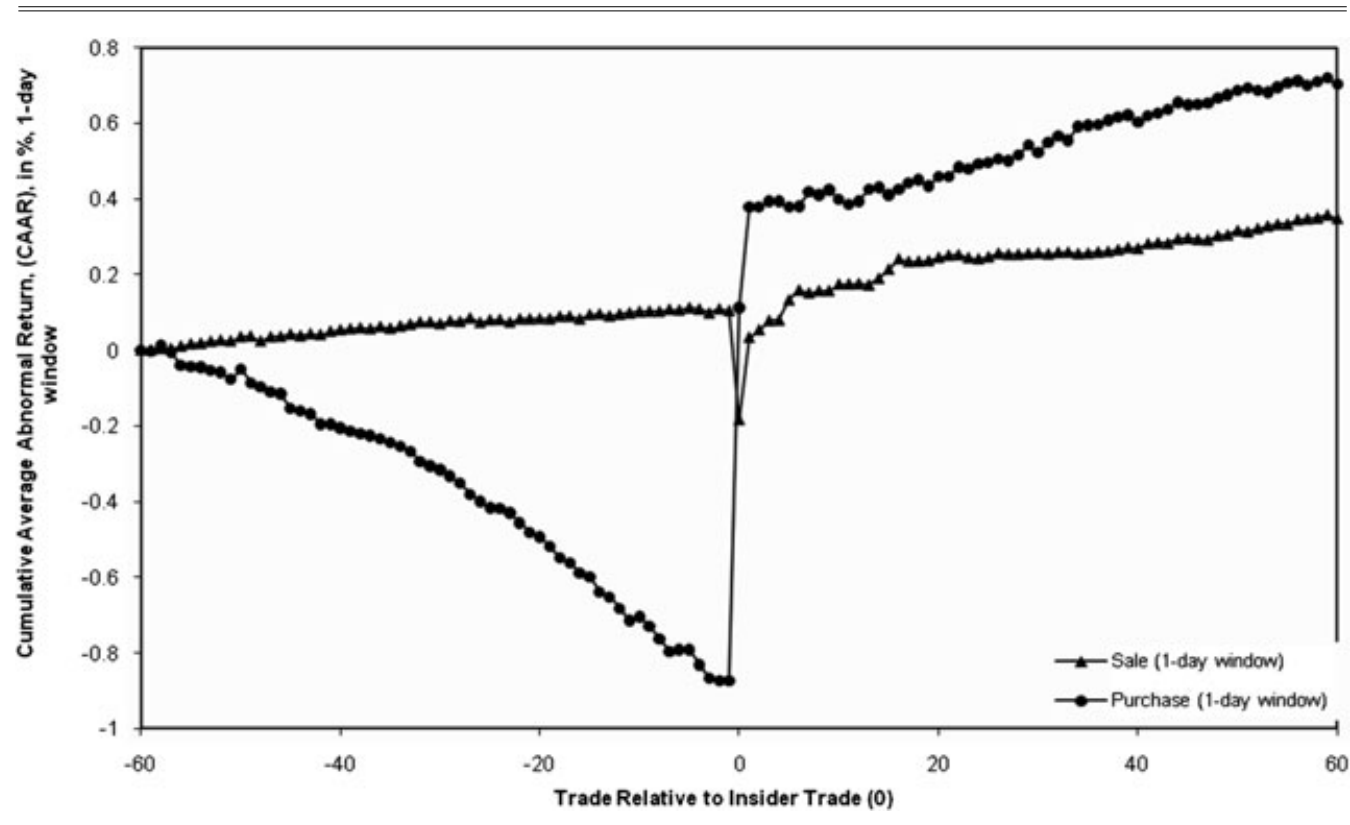

insiders' purchases suggests that a purchase order from an insider generates additional purchase orders from market professionals, leading to continuing positive price effects. In contrast, an insider sale does not seem to generate piggy-backing subsequent trades. We now proceed to a more detailed and formal examination of the trade-by-trade price effects of insiders' transactions.

In the remainder of this paper, we focus on holding-period abnormal returns. We compute three groups of abnormal returns to study the initial impact of insider trades, subsequent price reaction, and price behavior before the insider trades, respectively. First, the initial impact of insider trades is examined using the abnormal return of Trade 1 to Trade 0 . This return (for the $i$ th insider trade) is computed as

$$
A R_{0, i}=\left(\ln P_{0, i}-\ln P_{-1, i}\right)-\left(\ln M_{0, i}-\ln M_{-1, i}\right) .
$$

Second, the subsequent price reaction is examined using the holding-period abnormal returns of Trade 0 to later trades. They are computed as

$$
A R_{t, i}=\left(\ln P_{t, i}-\ln P_{0, i}\right)-\left(\ln M_{t, i}-\ln M_{0, i}\right),
$$

where $t>0$. The long-horizon returns show whether the initial impact of insider trades reverses, persists, or further increases through trading. We further define the total price impact at the $t$ th trade to be $A R_{0, i}+A R_{t, i}$, the sum of initial and subsequent impacts. Third, to examine price behavior prior to insider trades, we compute holding period abnormal returns of trades prior to insider trades relative to Trade -1 as 


$$
A R_{t, i}=\left(\ln P_{-1, i}-\ln P_{t, i}\right)-\left(\ln M_{-1, i}-\ln M_{t, i}\right),
$$

where $t<-1$.

\section{B. Insider Purchases}

\section{Price Behavior}

We conduct separate analyses for insider purchases and insider sales. In Table II, we report the evidence regarding price behavior around insider purchases. These results are based on three trade size groups: 1) small trades (100-999 shares), 2) medium trades (1,000-9,999 shares), and 3 ) large trades or block trades (10,000 shares or greater). Within each trade size group, we report results on abnormal returns of Trades $-60,-15,-5$, and -2 to Trade -1 ; abnormal return of Trade -1 to Trade 0 ; and abnormal returns of Trade 0 to Trades $1,2,5,15$, and 60 . All these trades are required to be executed on the same day as the insider trades. ${ }^{7}$ For each abnormal return, we compute the following statistics: 1) mean abnormal return, 2) $p$-value from the $t$-test for testing if the mean abnormal return is zero, 3) median abnormal return, and 4) $p$-value from the signed rank test to determine whether the median abnormal return is zero. We also computed $p$-values using an alternative method. In order to account for possible dependence in the data, we calculated standard errors and, consequently, the $p$-values in the spirit of Fama and MacBeth (1973). Following their procedure, we computed mean abnormal returns for each month of the 180 -month sample period. We utilized the monthly variability in the abnormal mean returns to compute the $p$-values.

First, let us examine price behavior before insider purchases through the abnormal returns of Trades $(-60,-1),(-15,-1)$, and $(-2,-1)$. If any of the mean or median abnormal returns are negative, it indicates that prices, on average, have declined from that trade to Trade -1 . We find that for all trade size groups, the mean abnormal returns before insider purchases are often significantly negative. For instance, the mean abnormal returns of Trades $(-60,-1)$ and $(-15$, -1 ) are -86 basis points and -27 basis points for the small trades, -94 basis points and -31 basis points for the medium trades, and -79 basis points and -38 basis points for the block trades, respectively. These numbers demonstrate a consistent and significant trend of declining prices prior to insider purchases regardless of trade size. We observe the same pattern from median values as well. Median abnormal returns of Trades $(-60,-1)$ and $(-15,-1)$ are -36 and -8 basis points for the small trades, -33 and -5 basis points for the medium trades, and -24 and -4 basis points for the large trades, respectively. All values are statistically significant.

The initial, contemporaneous price impact (mean abnormal return of Trade -1 to Trade 0 ) of insider purchases are about 97 basis points for the small trades, 102 basis points for the medium trades, and 102 basis points for the large trades. The initial impact of all trade size groups is highly statistically significant. Moreover, the initial median abnormal returns are also positive and significant with 21,20 , and 25 basis points for each trade size group, respectively. This finding suggests that the initial price impact is not produced by a few outliers.

For small trades, all of the mean abnormal returns of Trade 0 to Trades $1,2,5,15$, and 60 are significantly positive. Thus, prices continue to rise after insider purchases. There is no price reversal at all after the initial price impact. The subsequent price impact reaches 44 basis points at

\footnotetext{
${ }^{7}$ We also experimented with the three-trading-day (trades are required to be executed from one day before to one day after insider trades) and five-trading-day windows. All the results are qualitatively the same. Increase of number of trading days in the window makes the impact of insider trades more significant, as more observations from less liquid stocks are included in the analysis.
} 
胥

N

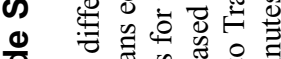

क च चै

วิ

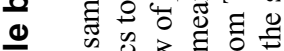

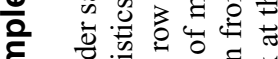

क

ᄒ

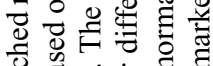

约

政

要

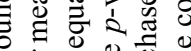

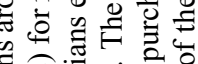

के चे

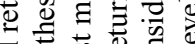

可

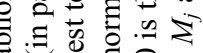

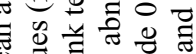

跑

is i

然:

定웡

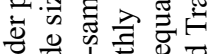

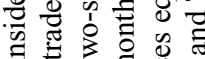

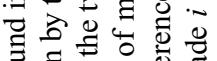

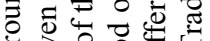

的

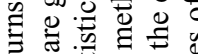

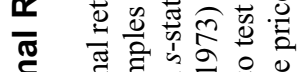

ह 를

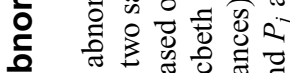

s 0 \%

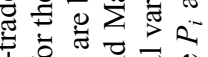

苋

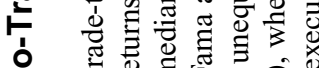

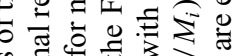

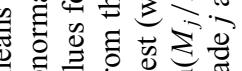

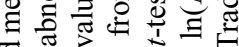

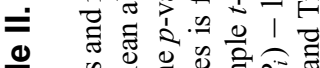

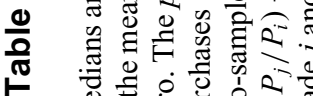

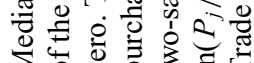

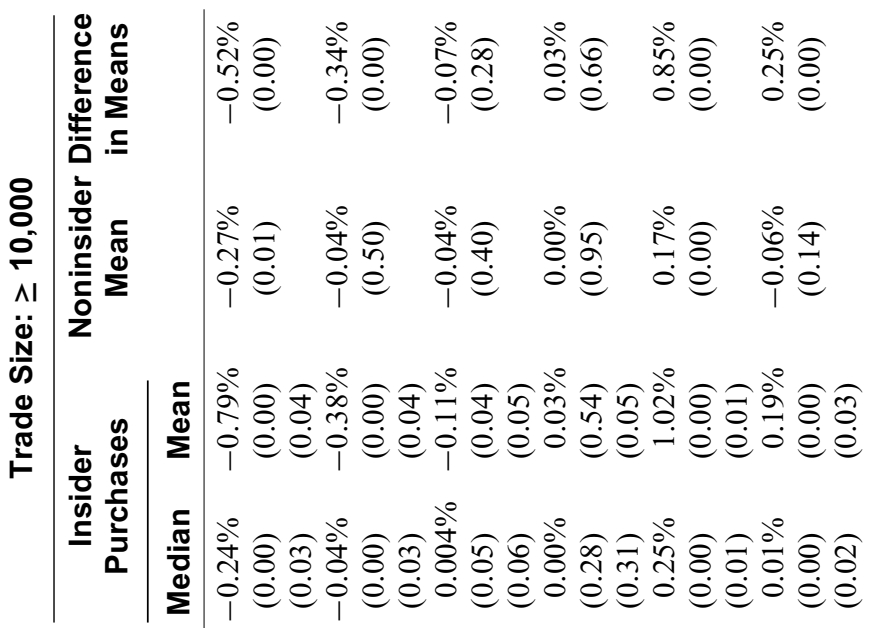

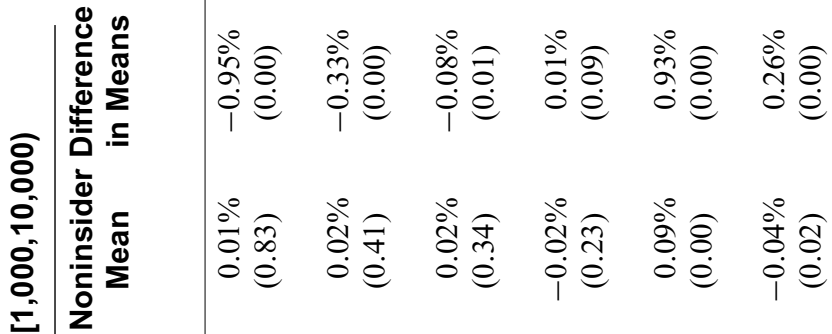

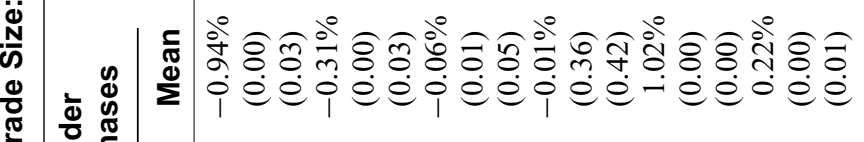

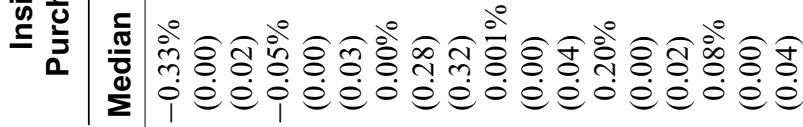

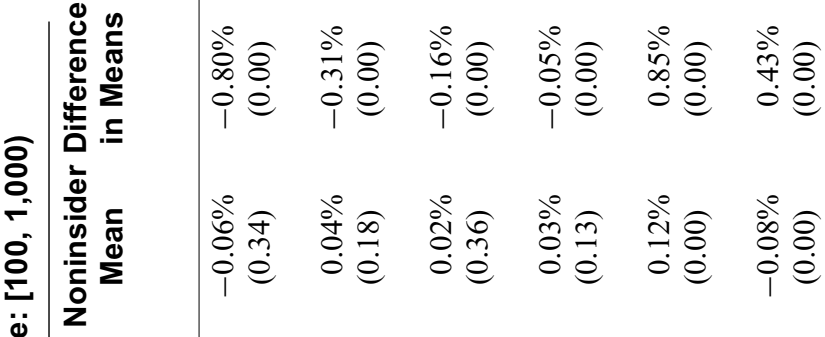

क |

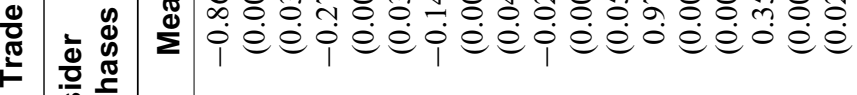

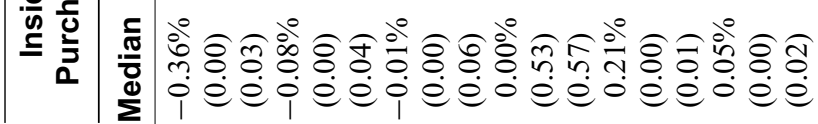

है

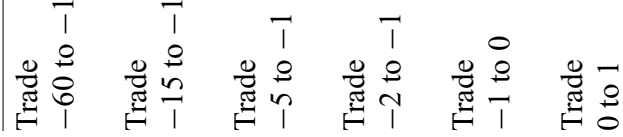




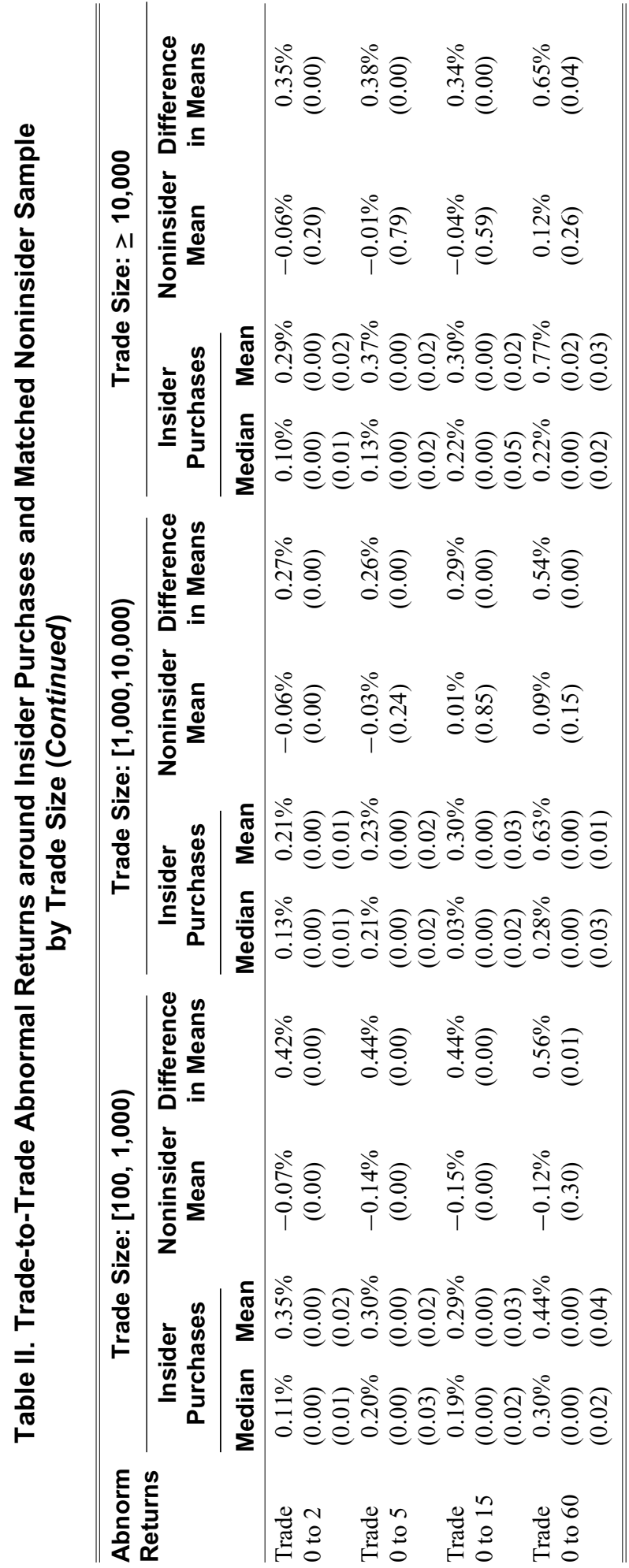


the 60th trade after insider purchases. The total price impact, defined as the sum of the initial and subsequent impacts, is $1.41 \%(=0.97 \%+0.44 \%)$ at the 60 th trade after the insider purchase. The median value of the total price impact is $51(=21+30)$ basis points at the 60 th trade. We see similar patterns in the mean abnormal returns and median abnormal returns of medium and large trade groups subsequent to the initial price impact. All subsequent returns are positive and significant. For example, prices rise by 63 basis points and 77 basis points for medium and large trades, respectively, beyond the initial impact by the 60th trade. Thus, using mean abnormal returns, the total price impact at the 60 th trade is $1.65 \%(=1.02 \%+0.63 \%)$ and $1.79 \%(=1.02 \%+$ $0.77 \%$ ) for medium and large trades, respectively. Using median abnormal returns, the total price impact is $48(=20+28)$ basis points and $47(=25+22)$ basis points for medium trades and large trades, respectively.

\section{Matching Control Sample}

While insider purchases appear to have both initial and subsequent price impact, we need to establish whether the price impact of insider purchases is different from those of noninsider trades with similar characteristics. In particular, we want to separate the effects of trade size, prior price movements, bid-ask bounce, and firm size from the fact that insiders are buyers. To proceed, we first classify the trade characteristics of insider purchases into:

1. Six groups in trade size: $(100-500),(500-1,000),(1,000-5,000),(5,000-10,000),(10,000-$ $50,000)$, and $>50,000$ shares.

2. Three groups in prior price change: $P_{0, i}>P_{-60, i}, P_{0, i}=P_{-60, i}$, and $P_{0, i}<P_{-60, i}$, where $P_{0, i}$ is the price of the insider trade and $P_{-60, i}$ is the price of the 60th trade prior to the insider trade.

3. Three groups according to whether the insider purchase prices are greater than, equal to, or less than the average prevailing bid-ask prices.

We then construct a random sample of noninsider trades by identifying another trade on the same stock during the same year that matches all three characteristics. We only search for those trades that were at least seven trading days apart from the corresponding insider purchases. It is possible that the control period likely differs from the insider trading period in stock price volatility, even with the match on prior price change. Given that market makers may be concerned about volatility, we examine this issue separately and determine whether there may be an additional need for a more explicit match on volatility (Andersen et al., 2001, examine the importance and necessity of considering stock volatility when using high-frequency data).

We calculated the volatilities using the 60 trades prior the insider trade and the 60 trades before the matched trade. We then compared the volatility measures to see whether there is a statistical difference. ${ }^{8}$ Using the trade-by-trade returns of the 60 prior trades, we calculated the time-series volatility for each insider purchase separately. We then did the same for the matched trade and compared the average volatilities. These volatility measures are $0.0993 \%$ and $0.0959 \%$ based on the insider trades and the matched trades, respectively. The $F$-test does not reject the

\footnotetext{
${ }^{8}$ We also used midpoints of bid and ask quotes to take into account the potential biases in cases of infrequent or nonsynchronous trading, in the spirit of Affleck-Graves, Hegde, and Miller (1994) and Nimalendran, Ritter, and Zhang (2007) with similar conclusions.
} 
null hypothesis of no difference between volatility values at conventional significance levels indicating that we also have a good match on volatility. ${ }^{9}$

Since we choose matching trades on the same stocks in the same year, in effect, we have a firm fixed-effects control for all firm-specific characteristics including firm size. The only difference is that insiders are buyers in the insider sample, while for the noninsider sample, buyers are randomly selected market participants. By using exactly the same methods as before, we compute the same trade-to-trade abnormal returns around these noninsider trades. We then compare the price impacts of the two samples.

In Table II, we report mean abnormal returns for both insider and noninsider trades and the $p$-values from testing the differences of the two means. The mean abnormal returns of prior trades to Trade -1 are negative for the insider purchases indicating declining prices prior to the trade. Conversely, noninsider trades generally have insignificant prior price changes from Trade -60 to Trade 0 . The two samples differ significantly in their price impact. For small, medium, and large trades, the initial impact (mean abnormal return of Trade -1 to Trade 0 ) of insider purchases is larger than that of noninsider trades, and the difference is significant at the $1 \%$ level. The initial impact of noninsider trades is also positive. However, the subsequent price behavior after Trade 0 is very different between the two samples. We have seen that insider purchases result in further subsequent price impact, as the mean abnormal returns of Trade 0 to Trade 60 are 44, 63, and 77 basis points for the small, medium, and large trades, respectively. In contrast, in the noninsider sample, the mean abnormal returns of Trade 0 to Trade 60 are all insignificant with $-12,9$, and 12 basis points. The subsequent return has virtually reversed all the initial impact of the noninsider trades in the small trade group. There is also a temporary price reversal from Trade 0 to Trade 5 for the medium size trades and from Trade 0 to Trade 15 for the large size trades after the initial impact. ${ }^{10}$

\section{Piggy-Backing on Insider Trades and Trading Intensity}

Our next task is to investigate the extent to which market professionals use their recently discovered knowledge regarding the arrival of an insider trade. First, piggy-backing on insiders' trades is unlikely to be illegal. ${ }^{11}$ Second, since we do not have access to proprietary data about market professionals' trading decisions or their inventory positions, we examine the number of trades and the direction of trades around insiders' transactions. Given that insiders do not publicly report their trades for anywhere from 2 to 40 days, at the time of their trade only the market professionals may be aware of the insiders' orders. Of course, another possibility is that insiders themselves may follow up their initial trades with subsequent trades. We rule out this possibility later in the paper. We expect that market professionals will want to imitate insiders' trades to take advantage of the insiders' information after they execute the order. They will want

\footnotetext{
${ }^{9}$ As an alternative, we computed the cross-sectional volatility of the returns obtained from the 60th and 59th trades prior to all insider trades and recorded the average. We repeated the computation for the prior returns (based on 59th and 58th trades, 58th and 57th trades, etc.). The average of these volatilities is $0.1083 \%$. Alternatively, the average of the volatilities obtained from the matched noninsider trades using the same procedure is $0.1042 \%$. These two measure are, again, not statistically different. We repeated the analysis by using both the 60 trades before and 60 trades after the insider (and the matched) purchase with similar conclusions.

${ }^{10}$ Including days with duplicate insider trades leaves the results based on median returns virtually unchanged for all trade sizes. For mean return based results, large trades are again unaffected while small trades demonstrate a small attenuation. Hence, our results are not sensitive to Filter 4.

${ }^{11}$ We know of no prosecutions in an insider piggy-backing case. Even the US attorney for Manhattan, James Comey, stated that indicting Martha Stewart for insider trading in a piggy-back case would have been unprecedented. See Forbes, "Martha's Goose on Slow Burn," June 5, 2003.
} 
to buy following an insider purchase, and sell following an insider sale for either proprietary trading accounts or favored clients' trading accounts. Moreover, they will want to do this quickly before others begin to exploit the same information and reposition prices. Consequently, if market professionals use the information about insiders' trades, we would anticipate the trading activity to intensify. Moreover, we expect market professionals to put in market orders and shift order imbalances in the same direction as the insider trade.

The intensity of trading activity is examined in Figure 2. In the top portion of the figure, we compute the number of trades within each 10 -second interval, five minutes prior to and five minutes after insiders' trades. For each firm, we then divide the number of trades by the average number to normalize the intensity. We then average these across insiders' trades to compute the average trading intensity.

This figure indicates that there is nothing unusual occurring prior to insiders' trades. However, the arrival of an insider purchase order increases the trading intensity (number of trades) immediately. Following insiders' purchases, trading intensity increases by about $60 \%$ and stays at this level for roughly 20 seconds. This increase in trading intensity is significant at the $1 \%$ level. Trading intensity then begins to taper down after this point. However, even after five minutes, trading intensity is still approximately $10 \%$ above the preinsider trading intensity level. Figure 2 is consistent with the hypothesis that market professionals increase their trading activity as a result of insiders' purchase orders.

The upper portion of Figure 2 also illustrates the changes in trading intensity following insiders' sales. Immediately following insiders' sell orders, trading intensity increases by about $20 \%$. This number is significant at the $10 \%$ level. However, the increase in trading intensity immediately tapers off to normal levels one minute after the insiders' sell order. This evidence suggests that insiders' sell orders do not generate as much subsequent trading activity as insiders' purchase orders.

We also replicated trading intensity using number of shares traded instead of number of trades. These results are similar and are summarized in the bottom portion of Figure 2. Following insiders' purchases, the number of shares traded rises by more than $50 \%$. This increase is significant at the $1 \%$ level. Even after five minutes, the increase in trading intensity is $25 \%$ above the preinsider purchase levels. Following insiders' sales, number of shares traded increases by $15 \%$. This increase is statistically significant at the $10 \%$ level.

\section{Piggy-Backing on Insider Trades and Order Imbalances}

While Figure 2 reveals an increase in trading activity immediately following insiders' trades, it does not tell us anything about the direction of increased trades. To determine whether higher trading intensity occurs in the same direction as insiders' trades, we compute order imbalances. Following the literature, we define order imbalance as the net difference between buyer- and sellerinitiated orders around an insider trade (we exclude insider trade itself from this computation). Order imbalance can generally be defined over a certain time period or for a certain group of sequential trades. A trade is defined as buyer- or seller-initiated based on how close it is to the prevailing bid-ask quote. The prevailing quote is determined, as in Section I.B, following Lee and Ready (1991). The Lee and Ready (1992) algorithm classifies a trade as buyer-initiated if it is closer to the ask price of the prevailing quote. Similarly, a trade is seller initiated if it is closer to the bid price of the prevailing quote. If the trade is at exactly the midpoint of the quote, a tick test is used. If the last price change prior to the trade is positive, the trade is classified as buyer initiated. Alternatively, the trade is seller initiated if the last price change prior to the trade is negative. 
Figure 2. Normalized Trading Intensity around Insiders' Trades

The top figure is for the normalized number of trades, the bottom figure is for normalized number of shares.
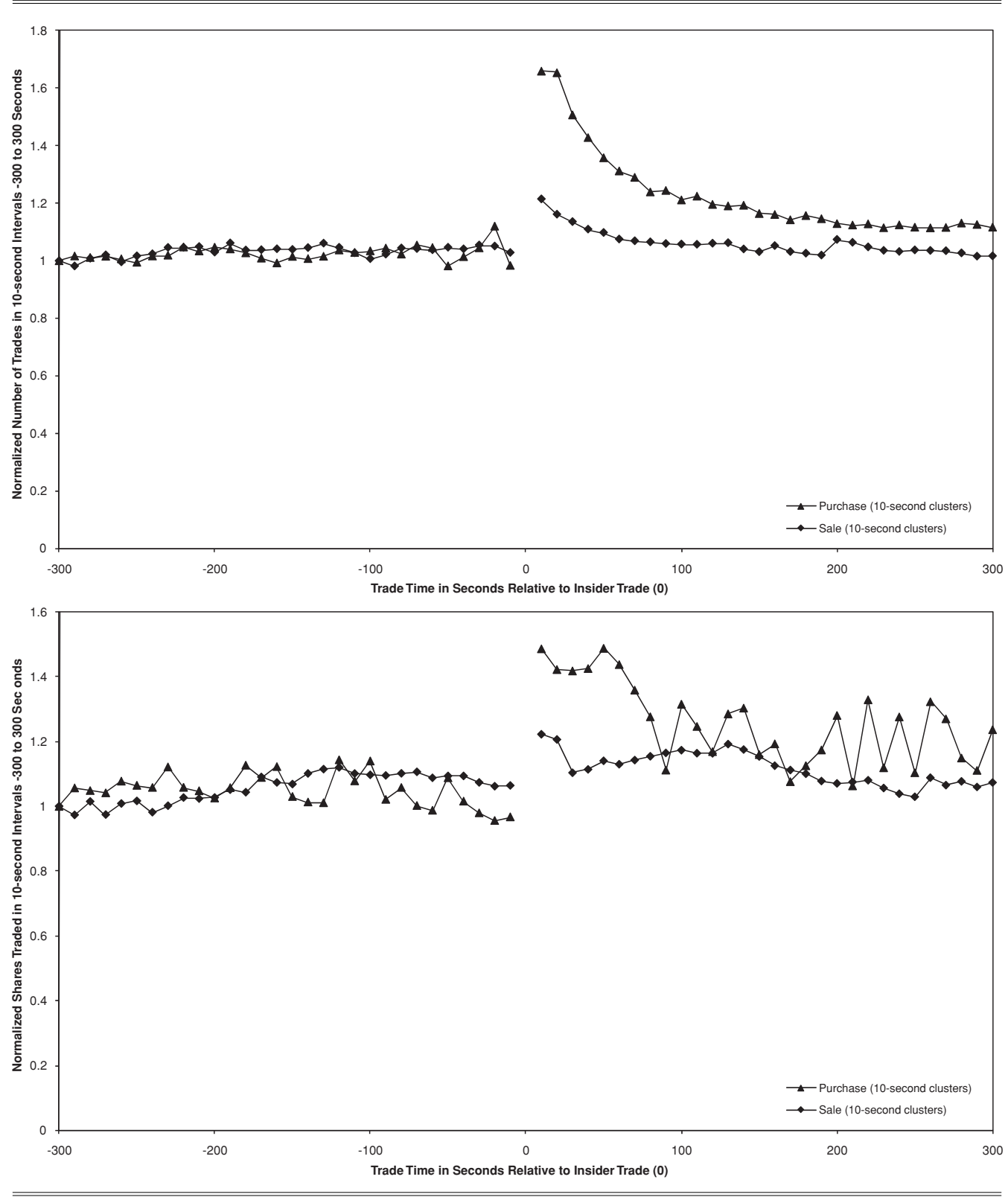

The price and volume information of the 60 trades before and after each insider trade in relation to their corresponding prevailing bid-ask quotes is used to define three different order imbalance measures following Chordia, Roll, and Subrahmanyam (2005). In order imbalance in numbers (OIB\#), a trade is buyer (seller) initiated if it is given a value of $1(-1)$. Order imbalance in volume (OIBsh) assigns the positive (negative) value of the number of shares to the 
buyer- (seller-) initiated trade. Finally, order imbalance in dollars (OIB\$) assigns the positive (negative) value of the product of the share price with the number of shares traded to the buyer(seller-) initiated trade. The first measure, OIB\#, disregards the size of the trade, counting small orders equally with large orders. The second and third measures weigh large orders more heavily.

Figure 3 illustrates the cumulative order imbalances around the insider trades. ${ }^{12}$ Initially, between trades -60 to -30 , the cumulative order imbalance is flat, indicating neither buying nor selling pressure in the marketplace due to market orders. Starting around trade -20 , sell-initiated orders predominate and the cumulative order imbalance begins to decline sharply. This indicates negative sentiment in the marketplace prior to insiders' purchases consistent with the price picture in Figure 1.

The arrival of the insiders' purchase orders (whether it is a market or limit order) completely reverses the order imbalances. Following insiders' purchases, the order imbalance pattern reverses and increases. We see similar patterns in cumulative normalized OIBsh and OIB \$ plots as well. It is evident that the orders following insiders' purchase orders also are buyer initiated. For all three measures of order imbalances, increases in order imbalances are significant at the $1 \%$ level. Our evidence thus far establishes that the arrival of insiders' purchase orders leads to sustained price increases, increase in trading intensity, and a predominance of buyer-initiated orders. Given that only market professionals may be aware of the insiders' purchase orders, the evidence is consistent with piggy-backing by market professionals. ${ }^{13}$

Piggy-backing on insider trades provides another mechanism for market professionals to reduce their adverse selection costs and allows them to offer reduced trading costs overall. We now examine whether greater initial stock price reaction, as well as piggy-backing of insider trades, facilitates greater incorporation of insider information into prices than in noninsider trading cases. To formally investigate this issue, we consider a vector autoregression (VAR) model below, following Hasbrouck (1991a).

\section{Measuring Speed and Degree of Information Incorporation into Prices}

We use a simple linear bivariate model where, following the Hasbrouck (1991a) notation, the interaction between the price change, $r_{t}$, and the trade indicator variable, $x^{0}(+1$ for a buy order and -1 for a sell order) are examined. In order to distinguish the influence of insider trades, the original VAR model is augmented to measure the additional impact, if any, of insider trades. The dummy variables, $D_{i}$, which are defined to be equal to one if the trade is an insider trade and zero otherwise, are multiplied with the augmented portion to estimate the difference in variable interactions between insider-informed trades and noninsider, or uninformed, trades

$$
\begin{aligned}
& r_{t}=\sum_{i=1}^{60} \alpha_{1, i} r_{t-i}+\sum_{i=0}^{60} \beta_{1, i} x_{t-i}^{0}+D_{1} \sum_{i=1}^{60} \alpha_{2, i} r_{t-i}+D_{2} \sum_{i=0}^{60} \beta_{2, i} x_{t-i}^{0}+v_{1, t} \\
& x_{t}^{0}=\sum_{i=1}^{60} \gamma_{1, i} r_{t-i}+\sum_{i=1}^{60} \delta_{1, i} x_{t-i}^{0}+D_{1} \sum_{i=1}^{60} \gamma_{2, i} r_{t-i}+D_{2} \sum_{i=1}^{60} \delta_{2, i} x_{t-i}^{0}+v_{2, t} .
\end{aligned}
$$

\footnotetext{
${ }^{12}$ Once again, order imbalance values are normalized by dividing by the sum of the absolute order imbalance values of the 60 trades before and after each insider trade. The normalized values are then averaged for Trade -60 through Trade 60 , cumulated over the trades around insider purchases and insider sales separately, and normalized one more time so that the insider trade (Trade 0) is defined as zero. Order imbalance measures are scaled in alternative ways in other studies as well (Hughen and McDonald, 2006).

${ }^{13}$ These graphical patterns are similar for different insider trade characteristics. Order imbalance plots for NYSE versus NASDAQ listed companies, size of the trade, top executives versus other insiders, and small versus large companies are similar to those reported here. These results are not presented for brevity.
} 


\section{Figure 3. Cumulative Order Imbalances}

The imbalance values are based on number of trades (Oib\#), number shares traded (Oibsh), and dollar value of trade (Oib\$) around insider's purchases.

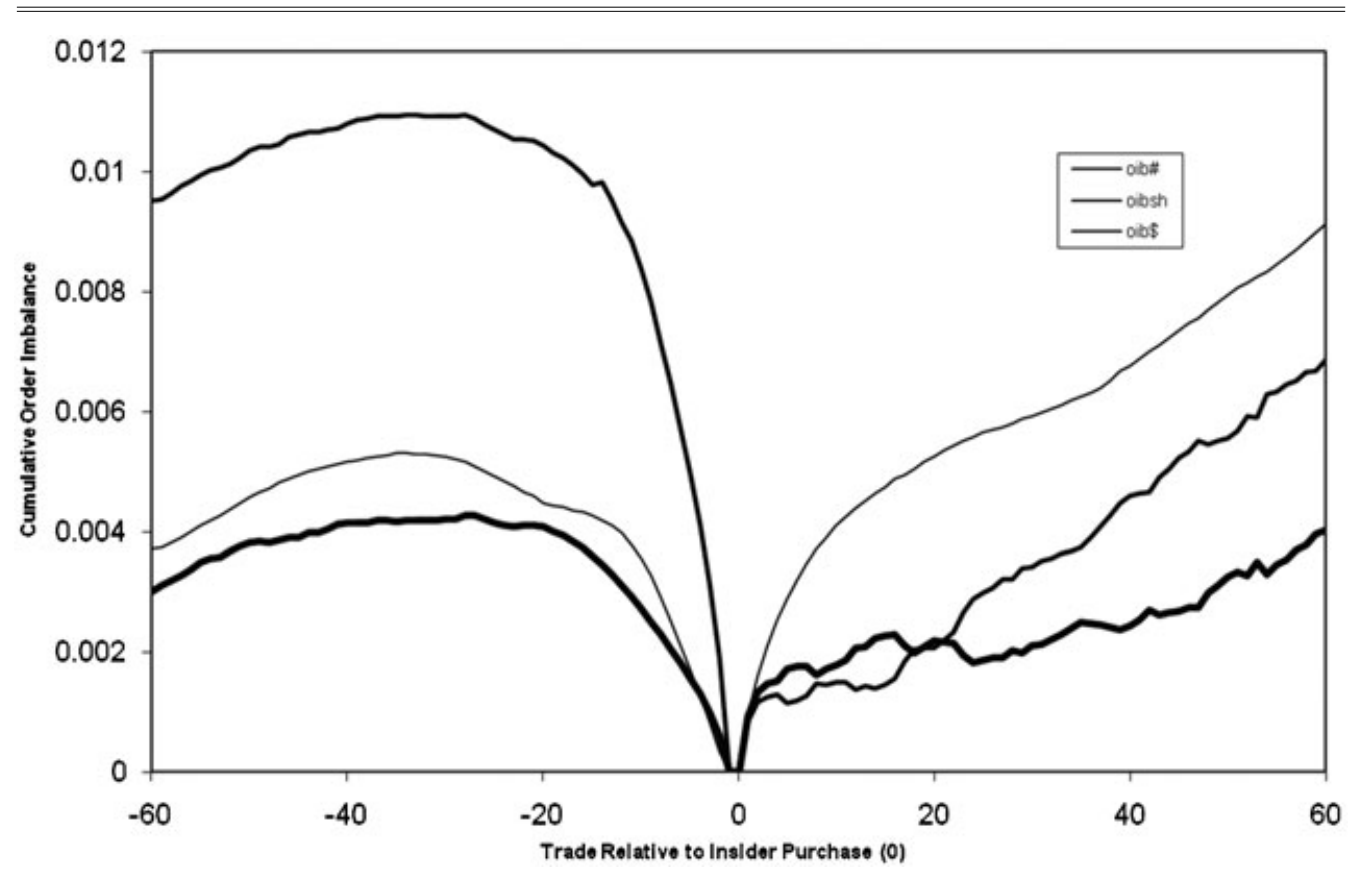

The summation for the trade variables start from $i=0$, while the quote revision sum begins at $i=1 .{ }^{14}$

The results are reported in Table III. The interactions between trades and quote reactions are different for informed insider trades and uninformed noninsider trades. There is a larger reaction to insider trades and this reaction is both faster and longer lasting when compared to noninsider trades. Although there are 60 variable lags as explanatory variables, only the first five are reported for brevity. In addition, the sum of the estimated 60 lag coefficients along with the corresponding $t$-statistic is reported.

Quote revision regressions are reported in the first group of columns. The coefficients of $x^{0}$, the trade indicator, indicate that after a purchase (sell) order, the quote midpoint is increased (decreased) by the market maker ( $\beta_{1,0}=0.096$ is significantly positive). The increase (decrease) is significantly larger if that order originates from an insider $\left(\beta_{2,0}=0.027\right.$ is additionally positive with $1 \%$ significance). If the order originates from an uninformed trader, longer lag quote revisions are insignificantly different from zero, summarized by the sum of the coefficients, $\sum \beta_{1, i}=-0.001$, which is not statistically significant. If the order originates from an insider, the

\footnotetext{
${ }^{14}$ Two econometric issues were considered. First, in order to determine the number of lags to be used as explanatory variables, Akaike information criterion and Sawa's Bayesian information criterion were used. Both criteria indicated the use of 60 variable lags as explanatory variables in the first VAR system and 30 lags in the second VAR system. We experimented with lags ranging from 20 to 60, and the conclusions remained the same. We report results based on estimations with the number of lags suggested by the information criteria. The second econometric issue was the possibility of nonstationarity. Analysis using Augmented Dickey-Fuller tests did not indicate evidence for nonstationarity.
} 
longer lags are also positive and significant (summarized by $\sum \beta_{2, i}=0.064$, which is positive and significant at 5\%). Thus, the market maker increases the quotes following both insider and noninsider purchases. Quote revisions following insider purchases are greater and continue for the next 60 trades resulting in a fuller reaction to insider purchases.

Trade regressions are reported in the second column. Noninsider purchases tend to follow price increases indicated by positive and significant $\gamma_{1, i}$ coefficients in both the short term and the long term $\left(\sum \gamma_{1, i}=1.218\right.$ is statistically positive at $1 \%$ significance $)$, while insider trades tend to exhibit a contrarian pattern as seen from negative $\gamma_{2, i}$ values (long term, $\sum \gamma_{2, i}=-1.595$ is significantly negative). Consistent with our previous results summarized in Figure 1, prior to an insider purchase (sale), the stock prices drop (rise). The coefficients of past trade variables, $\delta_{*, i}$, indicate the typical positive autocorrelation that Hasbrouck (1991a) reports. Buy (sell) orders are followed by buy (sell) orders and we do not see evidence of reversals in the long run. Insider trades also demonstrate the same tendency to follow previous insider trades in the same direction as the dummy variable coefficient is insignificantly different from zero at conventional levels.

While not revealed here, we also estimated a nonlinear VAR system. In addition to quote revision and trade indicator variables, we also included the signed trade size and the signed quadratic trade size. The nonlinear system produced similar results to the linear system. As demonstrated before in the $r_{t}$ estimation, if the order is uninformed, the net market maker reaction is an insignificant change in the opposite direction. Conversely, if the order is from an insider, the net effect is significant and in the same direction as that of the insider trade. The quadratic trade volume exhibits an opposite, but insignificant, impact on quote revision. In the case of insider trades, the trade volume has a concave impact on quote revision as documented in Hasbrouck (1991a).

The above results indicate that insider trades facilitate speedier incorporation of information into prices than in noninsider trading instances. There is a greater initial price reaction, followed by additional price changes in the same direction, resulting in fuller stock price reactions to insider trades. The piggy-backing of market makers on insider trades appears to be another mechanism for reducing adverse selection costs. We further examine this phenomenon with trade attributes below.

\section{Stock Price Reaction and Trade Attributes}

Our next task is to analyze whether the price reaction is dependent solely on the publicly observable trade attributes, or whether nonpublic attributes also matter. If nonpublic attributes, such as the hierarchy of an insider's relationship to the firm, are also reflected in the price reaction, then this finding would further strengthen the case that the presence of insiders is discovered and incorporated into the stock price at the time of trade. Previous research has indicated that the value of insiders' information depends on trade size, firm size, and insiders' status. In addition, stock price reaction is expected to be related to order type. For instance, Seyhun (1998) confirms that, historically, insider trades at small firms are more informative than those at large firms. Also, a larger volume of trading is associated with more valuable information than a smaller volume. Seyhun (1986) and Chiang and Venkatesh (1988) argue that large shareholders are less informed than officers and directors, and Griffiths et al. (2000) find that information content of trades is positively related to the order type on the Toronto Stock Exchange.

To take into account the interrelations among these variables, we estimate multivariate linear regressions for cumulative abnormal returns around insider purchases:

$$
\begin{aligned}
\text { CAR }_{t, T, i}= & \alpha_{0}+\alpha_{1} \text { MEDIUM }+\alpha_{2} \text { LARGE }+\alpha_{3} \text { SMALLCAP } \\
& +\alpha_{4} \text { TOPEXEC }+\alpha_{5} \text { OFFICER }+\alpha_{6} \text { MARKET }+\varepsilon_{t, i},
\end{aligned}
$$


where the regressors are respective dummy variables for medium trade size, large trade size, firm size Deciles 1-6, top executive insiders, nontop executive officers, and market orders. Recall that we define an insider purchase as a market order if its trade price is at the midpoint of the bid-ask price or above. Otherwise, it is a limit order. The dummy variable MARKET is equal to one for market orders and zero otherwise. Other dummy variables are similarly assigned values of one or zero.

The regression results are reported in Panel A of Table IV. The estimated coefficients of the dummy variables for medium and large trade size $\left(\alpha_{1}\right.$ and $\left.\alpha_{2}\right)$ generally corroborate our earlier results. The coefficients $\alpha_{1}$ (on MEDIUM) and $\alpha_{2}$ (on LARGE) are positive for the abnormal return of Trade -1 to Trade 0 . In other words, medium and large trades have a bigger initial price impact than small trades. Both coefficients for the subsequent returns are positive and significant, in general. However, there are also some statistically insignificant negative point estimates, suggesting that the total price impact of small insider purchases is not very different from those of medium insider purchases and large insider purchases. These results in the multivariate regressions are largely consistent with the previous findings in the univariate context. Even small insider purchases (between 100 and 1,000 shares) can be very informative and have a significant total price impact. On an intraday basis, the price impact of insider purchases is quite similar with respect to trade size. However, there is also some evidence of slightly higher total returns with trade size.

The estimates of coefficient $\alpha_{3}$ (on SMALLCAP) are significantly positive for the abnormal returns of Trade -1 to Trade 0 and of Trade 0 to most subsequent trades. Thus, insider purchases in smaller firms result in significantly higher initial and subsequent price impacts than those in larger firms. On an intraday basis, evidence indicates that insiders' purchases in small firms are more informative than those of large firms.

We now consider price reaction to then nonpublic information about insiders' type. At the time of the trade, only some market professionals may be aware of the insider trading and specifically the insider's relationship to the firm. If the insider's identity does not matter, then the price reaction should be explained by publicly observable trade characteristics such as firm size, trade size, and order type. However, if market professionals pay attention to the identity of the insider, then the hierarchy of the insider's relationship to the firm will also matter.

Panel A indicates that the estimates of the coefficients $\alpha_{4}$ and $\alpha_{5}$ (on TOPEXEC and on OFFICER) are significantly positive for the abnormal return of Trade -1 to Trade 0 . This suggests that after controlling for observable characteristics, the market's initial reaction to purchases by top executives is strongest, followed by that of officers and large shareholders. This finding is consistent with the scenario that the identity of insiders provides additional information to market participants.

\section{Order Types}

Next, we examine the effect of order types on stock price reaction. Panel A of Table IV confirms that the estimates of coefficient $\alpha_{6}$ (on MARKET) are also positive for the abnormal return of Trade -1 to Trade 0 but negative for the later abnormal returns. Apparently, the price impacts are not simply driven by the order type. To get a fuller picture, we further partition insider purchases into market and limit orders, and analyze the price impact of these two subsamples. For comparison, we also conduct the same analysis on the noninsider sample. These results are reported in Panel B.

Let us first look at the results on limit order insider purchases. The mean abnormal return of Trade -1 to Trade 0 is $-0.50 \%$ due to the definition of limit orders. However, following Trade 0 , 
$\dot{8} . \dot{0}$ 近

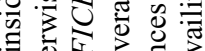

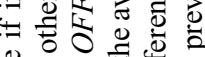

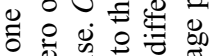

N.

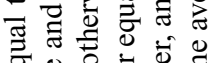

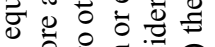

.

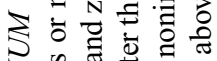

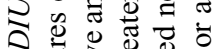

可部施

出 崩 8

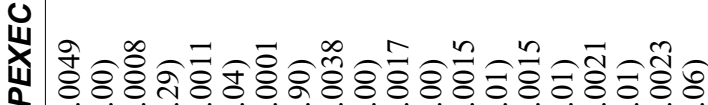
o

व

0

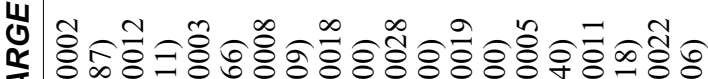
ذإ

ฟิ

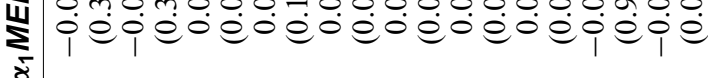
¿

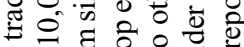

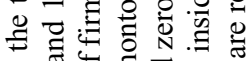

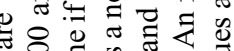

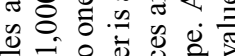

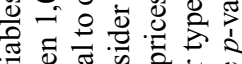

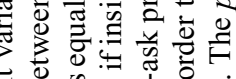

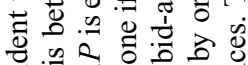
एँ

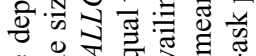

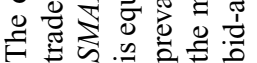

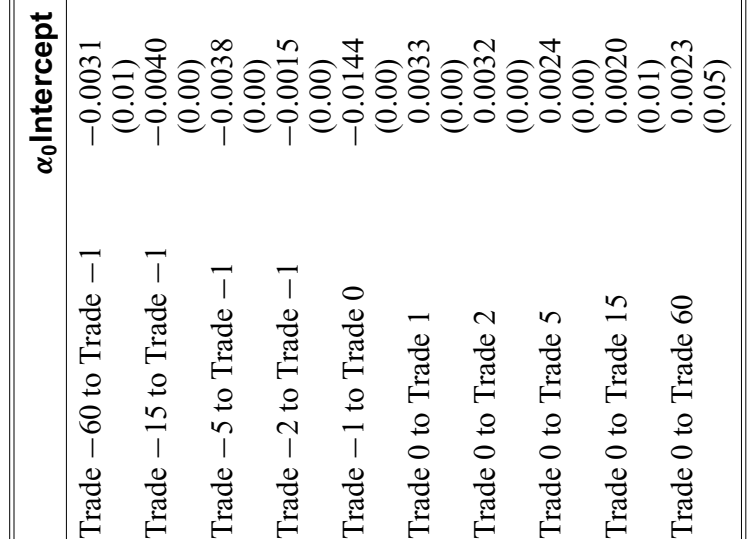




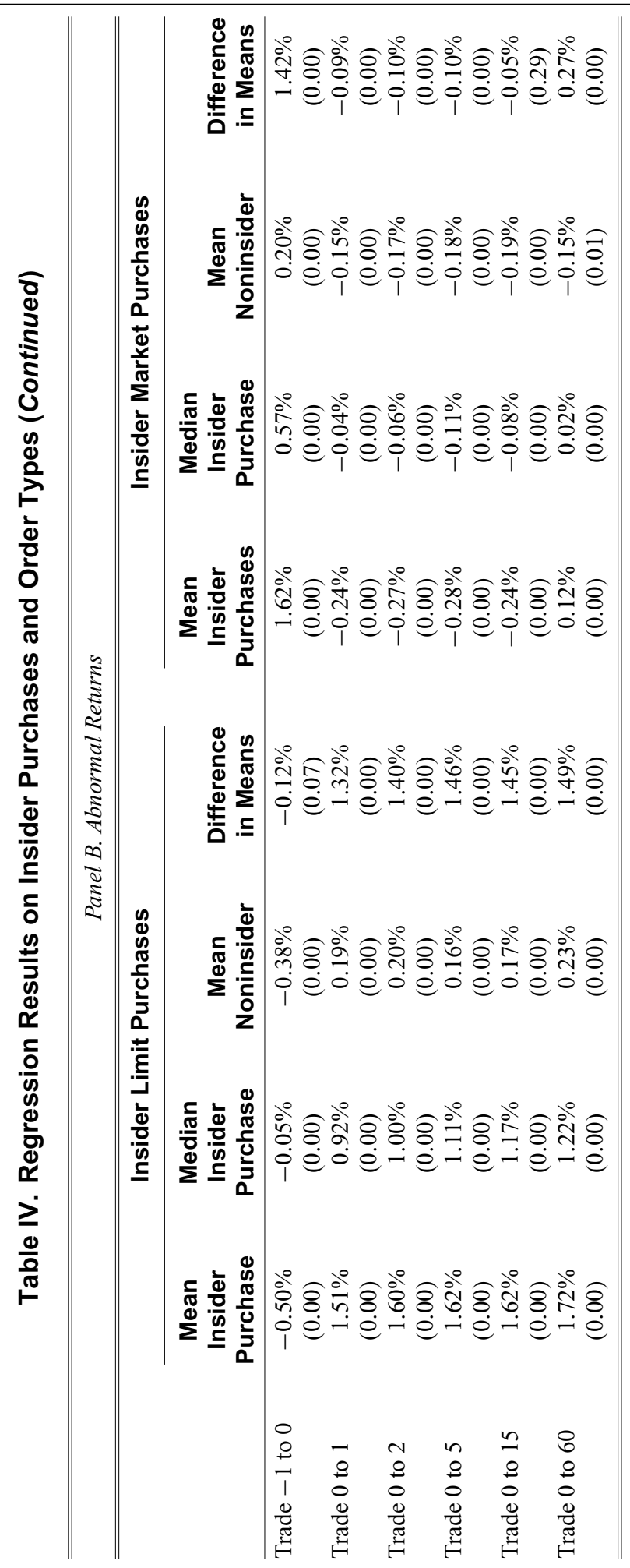


prices steadily rise and the mean abnormal return of Trade 0 to Trade 60 reaches $1.72 \%$. Hence, following their limit orders, insiders' profit averages $1.72 \%$. This evidence indicates that stock prices drift upward significantly in reaction to limit purchases. The same pattern is also found in the median abnormal returns of limit insider purchases. In comparison, the limit orders for noninsider trades result in a similar initial price impact of -38 basis points, but a subsequent price impact of only 23 basis points at the 60th trade, which is less than the absolute value of the initial impact. While the initial price impact between insider and noninsider limit purchases is statistically insignificant, subsequent returns of insider limit purchases are all statistically higher than those of noninsiders. The large and sustained price increase after limit insider purchases is unique to the insider trades.

Panel B also reports the results for market insider purchases. These purchases create an initial price impact of 162 basis points, which is significantly larger than the 20-basis-point impact of the noninsider market trades. There is a further subsequent price impact of 12 basis points at the 60th trade. Hence, following their market orders, insiders' profits average only 12 basis points. This is much lower than the 172 basis points on the subsequent impact of insider limit purchases.

This evidence indicates that insiders' limit purchases are much more profitable as they avoid paying the bid-ask spread for execution immediacy. Our finding suggests that some insiders are patient in taking advantage of their private information and they use limit orders to gain better control over prices if their private information is long lasting and will not be accompanied by a rapid corporate announcement to the market. The insiders' market purchases do result in quicker dissemination of private information on a trade-by-trade basis, but other market participants detect and act on insiders' purchases regardless of the order type.

Our evidence so far corroborates some of the findings from the literature. Similar to Hasbrouck (1991a, 1991b), we also find that the price impact is not immediately completed. Instead, the price impact continues for the rest of the day. The price impact in our study also tends to increase with trade size and is most pronounced in smaller firms. This is consistent with the evidence in Easley, Kiefer, O'Hara, and Paperman (1996), who find that information-based trading is higher in smaller firms. Our evidence also corroborates the findings in Harris and Hasbrouck (1996), who conclude that informed traders should do better by submitting limit orders rather than market orders using SuperDOT trading even after taking the probability of execution into account. The market microstructure and order type are also important factors as demonstrated in Jakob and Ma (2005). We find that conditional on execution, insiders realize greater profits (172 basis points) from limit orders than they do from market orders (12 basis points). These results suggest that when insiders have monopolistic access to long-lived information, they can and do exploit this better by submitting limit orders and thereby avoid paying for immediacy of execution. Our evidence also cautions against characterizing market orders as information motivated trades and limit orders as liquidity motivated trades.

\section{E. Order Imbalances and Trade Attributes}

We further examine the impact of order imbalance on abnormal returns around insider transactions in multivariate linear regressions. We explore the interaction of order imbalance with other trade attributes such as trade size, firm size, order type, and insiders' status in time series regressions. All three order imbalance measures are used separately in the regressions of the abnormal returns in insider purchases and insider sales reported in Table V. Panel A uses OIB\# as the independent order imbalance measure. Panel B uses order imbalance in volume, OIBsh, and Panel $\mathrm{C}$ uses order imbalance in dollars, OIB \$, in the regressions. The results suggest that order imbalances following insiders' trades contribute positively to the price impact of insider 


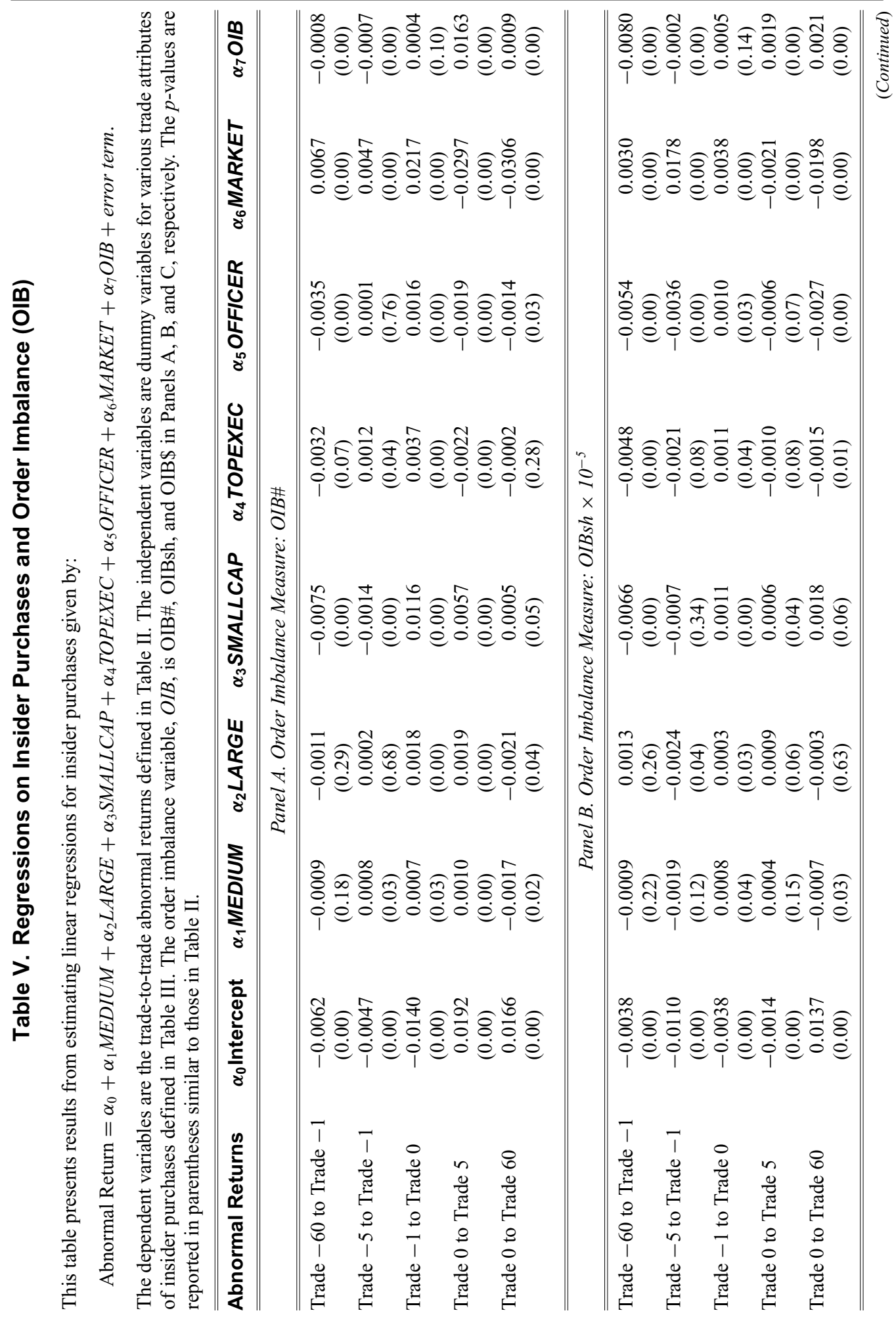




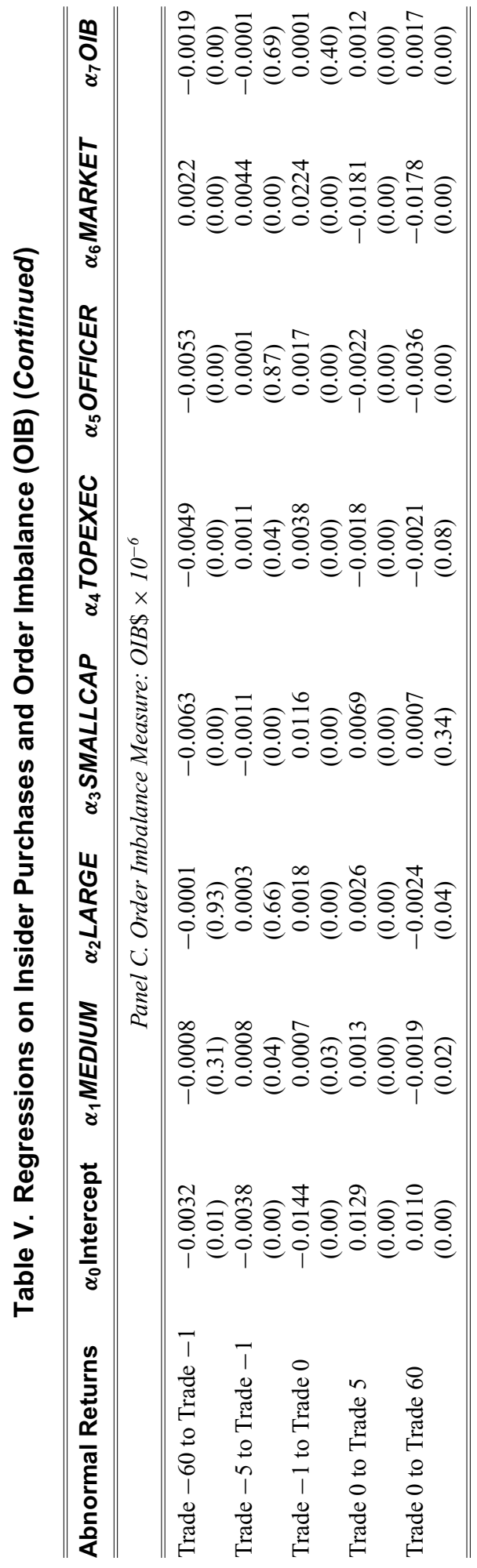


trades. In contrast, order imbalances prior to insiders' purchases contribute negatively to the price impact. This finding suggests that the arrival of the insider trade reverses the price impact of order imbalances.

Finally, we investigate the determinants of the reversals in order imbalances shown in Figure 3 using a multivariate regression analysis. Our dependent variable is the cumulative change in order imbalances for various holding periods from $(-1$ to +1$)$ to $(-60$ to +60$)$.

$$
\begin{aligned}
\text { OIB }_{t, T, i}= & \alpha_{0}+\alpha_{1} \text { MEDIUM }+\alpha_{2} \text { LARGE }+\alpha_{3} \text { SMALLCAP } \\
& +\alpha_{4} \text { TOPEXEC }+\alpha_{5} \text { OFFICER }+\alpha_{6} \text { MARKET }+\varepsilon_{t, i},
\end{aligned}
$$

where the regressors are respective dummy variables for medium trade size, large trade size, firm size Deciles 1-6, top executives, nontop executive officers, and market orders. The dummy variable MARKET is equal to one for market orders and zero otherwise. Other dummy variables are similarly assigned values of one or zero.

The multivariate regression results are reported in Table VI. Panel A presents regressions where the dependent variable is the cumulative change in the order imbalance based on numbers, OIB\#. Panel B and Panel C present regression results for the cumulative change in the order imbalance based on volume and dollar value, respectively. We observe from the panels that reversals in order imbalances (using all three measures) are more pronounced in small firms. Reversals in order imbalances also increase with insiders' trading volume. Larger purchases by insiders' are much more likely to lead to bigger reversals. Order imbalances also reverse to a greater extent when insiders place limit orders. Finally, even though insider trading information is not yet made public, order imbalance reversals are more pronounced for top executives' and officers' trades than they are for large shareholders' trades. All these effects are statistically significant at the $1 \%$ level. These findings are consistent with our previous evidence regarding the impact of insider trading.

\section{F. Insider Sales}

Thus far, our analyses have been for insider purchases. Given that there are almost twice as many insider sales as there are purchases, an examination of insider sales is warranted, starting with price behavior around insider sales by trade size groups. We first examine price behavior prior to insider sales through the abnormal returns of Trades $-60,-15,-5$, and -2 to Trade -1 . Both the mean abnormal returns and median abnormal returns prior to insider sales are mostly positive for small trades (100-999 shares), medium trades (1,000-9,999 shares), and large trades (more than 10,000 shares). All positive median returns are also significant. For instance, the median abnormal return of Trade -60 to Trade -1 is 5 basis points for small trades, 9 basis points for medium trades, and 5 basis points for large trades. This means that prices have been increasing prior to these insider sales.

The initial price impact (median abnormal return of Trade -1 to Trade 0 ) of insider sales is about -4 basis points for small trades, -12 basis points for medium trades, and -26 basis points for large trades. The initial impact of all trade size groups is statistically significant. The mean abnormal returns are all significantly negative as well. However, the overall initial price impact is completely reversed during the following trades. For instance, the median abnormal return of Trade 0 to Trade 60 is 13 basis points for small trades, 28 basis points for medium trades, and 40 basis points for large trades. Initial mean abnormal returns of $-5,-27$, and -49 basis points are also reversed with the subsequent mean returns of 34, 44, and 86 basis points from Trade 0 to Trade 60 for small, medium, and large trades, respectively. Thus, there is essentially no 


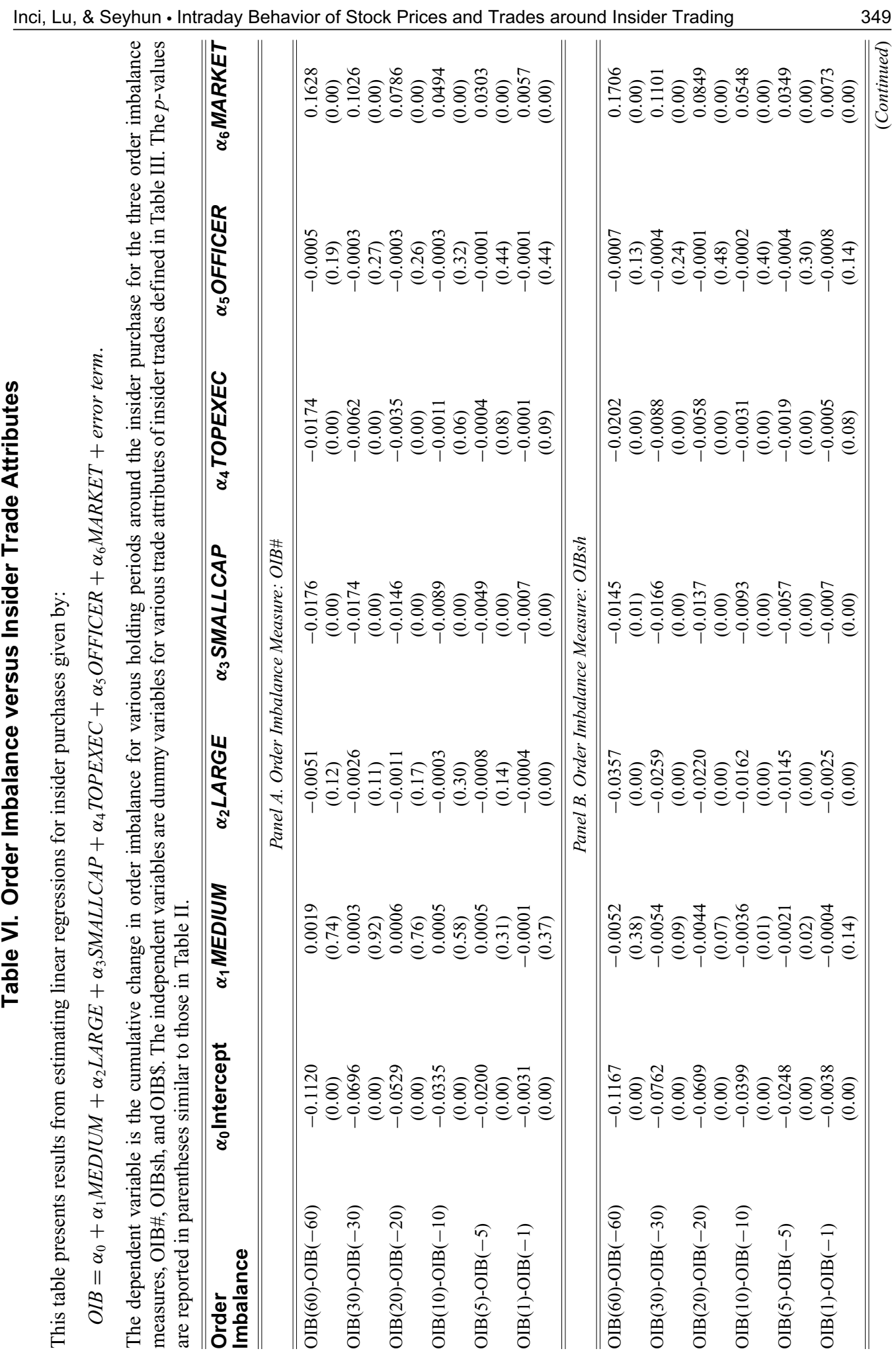




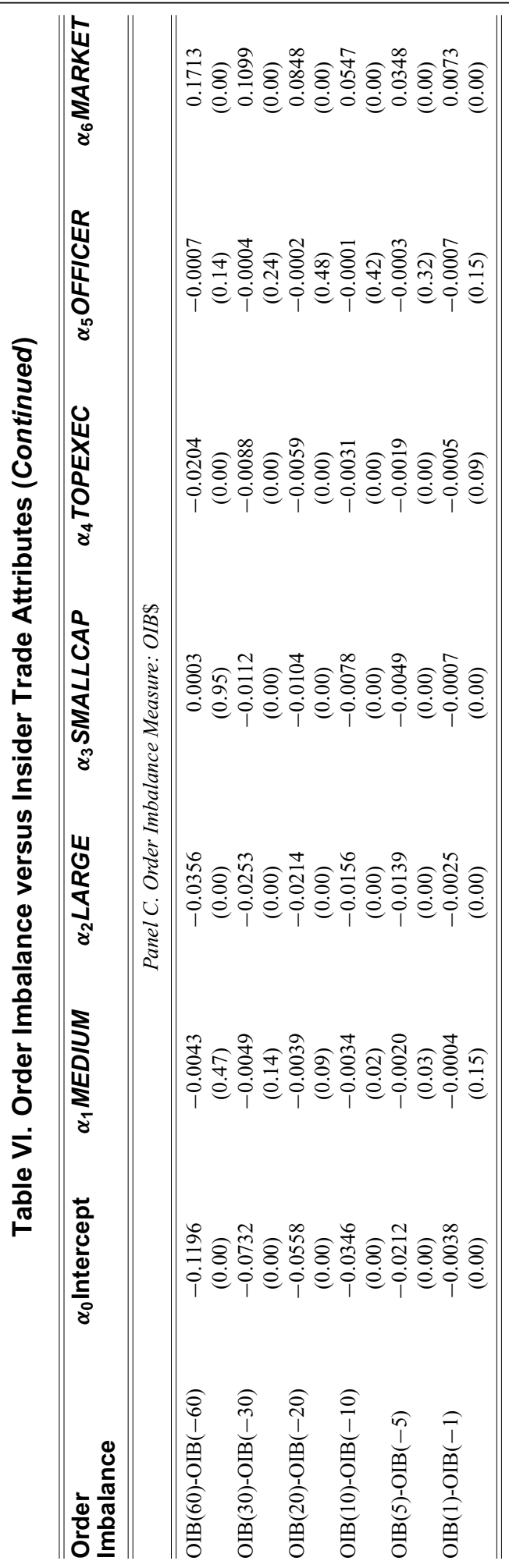


total impact from price decrease associated with insider sales. Insider sales only depress prices temporarily at best. Prices quickly resume their climb after Trade 0 .

We also compare the price impact of insider sales to that of a matched noninsider trade sample constructed in exactly the same manner as the random sample matching insider purchases. That is, the noninsider trades match the insider sales in terms of trade size, prior price movements, bid-ask bounce, and firm size. When compared to this random sample, insider sales are characterized by greater initial impact, but also greater subsequent reversals. The overall difference is small, however, and neither sample exhibits total price impact. For brevity, we do not report the above results, but they are available upon request.

We further estimate linear regressions of abnormal returns around insider sales on dummy variables for several types of sales: 1) medium trade size, 2) large trade size, 3) firm size Deciles $1-6,4)$ top executive insiders, 5) nontop executive officers, and 6) the order type of insider sales. The regression results are reported in Table VII. The estimates of the coefficients $\alpha_{1}$ (on MEDIUM), $\alpha_{2}$ (on $L A R G E$ ), and $\alpha_{3}$ (on SMALLCAP) are negative for abnormal return of Trade -1 to Trade 0 but are positive afterward. In other words, insider sales of larger trades and in smaller firms cause greater initial impact, but they also experience greater price reversals. Conversely, the coefficients $\alpha_{4}$ (on TOPEXEC) and $\alpha_{5}$ (on OFFICER) are significantly negative for the abnormal return of Trade -1 to Trade 0 and are negative and borderline significant for the abnormal return of Trade 0 to Trade 60 . Thus, sales of stock by top executives and officers decrease prices, both initially and subsequently, more so than sales by other insiders such as large shareholders.

Together with earlier evidence, these findings suggest that the lack of total price impact for the sales group is entirely due to large shareholders. Typically, large shareholders trade without information (Seyhun, 1998) and they trade large volumes of stock. Consequently, it is not surprising that sales by large shareholders do not generate a price impact by the end of the trading day.

In summary, we find that insider sales cause a significant initial price decrease but no total price impact (overall sample). The initial impact is quickly reversed in the trades following insider sales. Insiders are again contrarian since they typically sell after prices have gone up. There is, however, both an initial and a subsequent price impact for top executives' and officers' sales, though it is smaller than that of the purchases.

What causes weaker results for insider sales than for insider purchases? We know that insiders are often given stock options as compensation. Once these options become vested and move in the money, insiders typically exercise them, acquire the shares, and immediately sell the shares on the open market to rebalance their portfolio. Some executive options contain a reload feature that is only triggered when executives exercise these options and sell their existing shares to pay the exercise money. Consequently, some of insider sales are triggered for liquidity or portfolio rebalancing rather than for information purposes. In contrast, when insiders buy, it is more likely to be information driven. Market participants appear to understand these distinctions and treat insider sales as less informed than insider purchases (Seyhun, 1998). Consequently, insiders' sales do not appear to elicit as much of a price reaction as insiders' purchases.

We also investigated the initial and subsequent price reaction of insider trading separately for NYSE, AMEX, and NASDAQ. Given that AMEX and NASDAQ contain smaller firms, we also find somewhat stronger results for AMEX and NASDAQ. For insiders' purchases, the price impact from Trade -1 to Trade +1 equals 76 basis points for NYSE, 132 basis points for NASDAQ, and 249 basis points for AMEX. For insiders' sales, the price impact from Trade -1 to Trade +1 equals -9 basis points for NYSE, -39 basis points for NASDAQ, and -14 basis points for AMEX. For the sake of brevity, these results are not shown. 


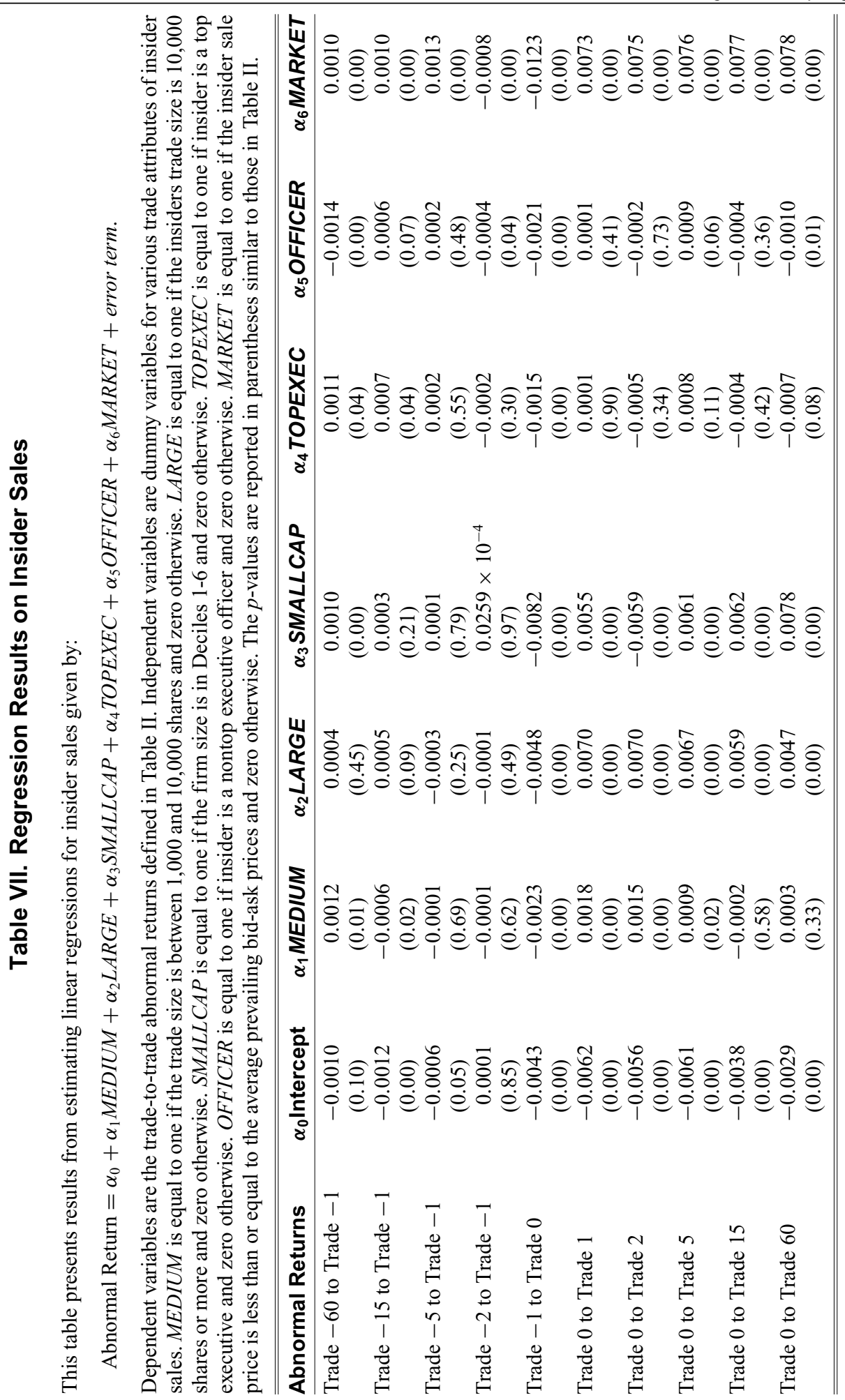


We also find that while there is a larger initial reaction for AMEX and NASDAQ, the subsequent price reaction to insiders' trades appears to be exchange related. For both NYSE and AMEX exchanges, the drift for purchases from Trades 0 to 60 is small and insignificantly different from each other. For NASDAQ, the drift from Trades 0 to 60 is about 42 basis points and it is significantly higher than that of NYSE. Our evidence suggests that the stock price reaction in NASDAQ takes longer to be completed suggesting less transparency for NASDAQ. This finding is similar to Garfinkel and Nimalendran (2003).

\section{G. Further Analysis and Robustness Tests}

\section{Bid-Ask Quotes}

We have so far used trade-to-trade abnormal returns to analyze the price impact of insider trades. To demonstrate that the detected price impact is not due to trade size, prior price movements, bid-ask bounce, or firm size, we have compared insider trades with matched noninsider trades. To further check the robustness of our results against bid-ask bounce, we replicate our analysis using returns based solely on ask price quotes for insider purchases and returns based only on bid price quotes for insider sales. Unlike transaction returns, the bid-to-bid and ask-to-ask returns will not be affected by the bid-ask bounce at all (Koski and Michaely, 2000).

The ask-to-ask returns based results for insider purchases are similar to those in Table II. Prior to insider purchases, quoted ask prices have been declining for all trade size groups. The initial price impact, measured by ask-to-ask returns, is 63 basis points for small trades, 43 basis points for medium trades, and 65 basis points for large trades. The median initial price impact with 15 basis points for small trades, 11 basis points for medium trades, and 33 basis points for large trades is significant and positive as well. Thus, the initial price impact is positive and significant regardless of the trade size group. Following insider purchases, quoted ask prices continue to increase, causing significant total price impacts whose magnitude is similar to those measured by trade-to-trade returns in Table II.

We also replicated the results on insider sales based on quoted bid prices only. The initial mean price impact of insider sales for the three trade size groups are now $-19,-35$, and -43 basis points compared to $-5,-27$, and -49 basis points measured by trade-to-trade returns. Initial price impact with median values is also all negative, statistically significant, and similar to the median values measured by trade-to-trade returns. Hence, the use of bid-to-bid returns attenuates the initial impact of larger trades, but not insider sales in general. Following insider sales, all initial impacts are reversed and bid prices resume their climb for the overall sample. Again, there is no evidence of a total impact of insider sales. In summary, the results based on bid-to-bid and ask-to-ask returns are essentially the same as those based on transaction returns.

\section{Isolated Insider Trades}

Thus far in our analysis, we have not considered how closely insider trades are clustered together. If insiders execute multiple trades during the day, what we measure as subsequent drift may actually be a contemporaneous reaction to a subsequent insider trade. To address whether the price reactions are affected by the presence of multiple insider trades, we consider a three-day window around an insider trade. We only choose insider trades that do not have other insider trades of the same firm the day before, during the day, or the day after the trade. This reduced subsample does not have any clustering complications.

The majority of the total of 117,179 isolated insider trades is sales, and approximately $40 \%$ are insider purchases. A rough breakdown of the insider trade size distribution indicates a slight 
skewness toward smaller sized trades. About $22 \%$ of trades have a size of fewer than 1,000 shares and $20 \%$ of the trades are block trades of more than 10,000 shares. The rest are between 1,000 and 10,000 shares. A majority of isolated insider purchases are small (33\% of all isolated purchases) as compared to block purchases (11\% of all isolated purchases). Alternatively, $26 \%$ of isolated sales are block sales and about $14 \%$ of sales have a trade size of fewer than 1,000 shares.

The evidence regarding price behavior around isolated insider purchases is very similar to those in Table II. We see a significant decline in prices prior to the isolated insider purchases. Both the mean and median abnormal returns are significantly negative, regardless of trade size. For example, median abnormal returns from Trade -60 to Trade -1 are -49 basis points for small trades, -46 basis points for medium trades, and -29 basis points for large trades. The initial price impact from Trade -1 to Trade 0 is positive, statistically significant, and very similar to the initial price impact reported in Table II. The median abnormal returns are 22 basis points for small trades, 21 basis points for medium trades, and 26 basis points for block trades. The subsequent price reaction is also positive and significant for each trade size group. The median abnormal return from Trade 0 to Trade 60 is 30 basis points for small trades, making the total price impact $52(=22+30)$ basis points. The total price impacts are 50 basis points and 46 basis points for medium and large trades, respectively. Initial, subsequent, and total price impacts measured by mean abnormal returns are also positive and significant. Mean returns increase with trade size group, indicating some evidence of higher returns related to the size of isolated insider purchase.

Price behavior surrounding isolated insider sales indicates a statistically significant price increase prior to insider sales. Mean abnormal returns are 11 basis points, 18 basis points, and 8 basis points from Trade -60 to Trade -1 , respectively, for small, medium, and large trades. The initial price impact is negative and significant. However, subsequent trades quickly and completely reverse the initial impact. The mean and median abnormal return values are very close to the trade-to-trade returns of the original, larger sample. As before, there is no total impact of the price decrease associated with isolated insider sales. In summary, the isolated insider trading sample virtually produces identical results when compared to the original sample. Clustering does not appear to explain our main results. The cumulative average abnormal returns (CAARs) of isolated trades in a one-day window are very similar to the ones presented in Figure 1 for the entire sample (the full set of results are not reported here for brevity but are available upon request).

\section{Additional Sensitivity Tests}

To determine if insiders abstain from exploiting earnings related information, we partitioned our sample into two groups depending on the proximity of insider trading to earnings announcement dates. Bettis, Coles, and Lemmon indicate that earnings announcement periods are clustered around the periods of the last week of January to mid-March, mid-April to the last week of May, the last week of July to the last week of August, and from mid-October to the last week of November. Hence, we analyze stock price reaction to insiders' trades separately for earnings clustered periods as well as nonearnings clustered periods. Our evidence suggests that the market reaction to insiders' trades is slightly greater during the nonearnings clustered periods. This is consistent with Bettis, Coles, and Lemmon that blackout periods do reduce the profitability of insider trading somewhat. Nevertheless, the differences are never large. Our findings suggest that taking into account blackout periods around earnings announcements does not affect our results. Our findings also suggest that the intensity of market reaction to insider trading is also 
not affected by the arrival of public information regarding earnings announcements (Bamber, Barron, and Stober, 1997, 1999; Fleming and Remolona, 1999).

Since surprise announcements may be reported late, they are likely to generate greater stock price reactions. Therefore, we use the $\mathrm{I} / \mathrm{B} / \mathrm{E} / \mathrm{S}$ (Institutional Brokers Estimates System) database and obtain the earnings announcement dates for all the companies in our sample for the sample period. We then focus on the insider trades that took place one day before, on the same day, and one day after the earnings announcement. These trades constitute a small fraction of the entire sample; $2.36 \%$ of insider purchases and $1.89 \%$ of sales surround earnings announcement dates. The market reaction is not dramatically different from the previous results. The long-term stock price reaction before and after the insider purchase around the earnings announcement is slightly subdued, while the immediate reaction is slightly higher. These differences from previous results are not statistically significant. For large insider sales, price reactions prior to the trade and the immediate reaction to the trade are slightly higher, while the subsequent reaction is somewhat lower. Overall, the results obtained from insider trades immediately around earnings announcements do not affect our conclusions.

Finally we examine the time series stationarity of our results. For this purpose, we break up our sample into three time periods: 1) 1988-1991, 2) 1992-1998, and 3) 1999-2002. As the number of insider transactions increase over time, the fraction matched falls slightly due to our screening procedures eliminating multiple trades and multiple matches. For example, the total number of insider trades is 217,753 in the first four years (1988-1991) as compared to 645,836 in the last four years (1999-2002) of the sample. In 1989, 7,473 of 53,202 insider trades are matched in the companies where there was an insider trade. In other words, $14.05 \%$ of the insider trades were matched in 1989. Alternatively, in 1999, 11,923 of 95,489 insider trades are matched in the companies where there was an insider trade. To clarify, $12.49 \%$ of the insider trades were matched in 1999 as opposed to $14.05 \%$ in 1989 . This is a statistically significant lower percentage. Similar differences are seen between the data from earlier years and from recent years as well. However, stock price reactions to insider trading do not indicate any meaningful differences over time.

\section{Conclusions}

We find that insider trading contributes to the informational efficiency of the stock market. Upon arrival, insiders' purchases are associated with significant initial and subsequent price impacts on a trade-by-trade basis. Prices rise, on average, by 100 basis points on insiders. Following insiders' purchases, prices continue to rise for the rest of the day by an additional 50 basis points. Insiders' sales also are associated with a significant initial price impact. Prices decline about 30 basis points upon the arrival of insiders' sales. Following officers' and top executives' sales, prices remain depressed throughout the day. For large shareholders' sales, initial price decline is reversed during the remainder of the day. When compared to noninsider trades, we find that market reaction to insider trades is quicker and more complete.

We find no price impact immediately prior to insiders' trades. There is no price increase prior to insiders' purchase orders, and there is no price decrease prior to insiders' sale orders. This evidence is consistent with the hypothesis that market professionals do not front run insiders' orders.

Insiders appear to be contrarian. Prices fall before insiders' purchases and rise before insiders' sales within the day. A potential explanation for this phenomenon is insiders' order types. A significant portion of insiders' trades are limit orders and are only executed if the stock prices 
move to the limit prices. Consequently, insiders' limit purchase orders are executed in a declining market, while insiders' limit sell orders are executed in a rising market.

Prices have been falling for at least 30 days prior to insiders' purchases and rising for more than 30 days prior to insiders' sales. On average, insiders not only buy at the lowest price within a day, but they also buy at the lowest price over a 61-day window. The timing of insiders' sales is similar, yet not as fortuitous as their purchases.

Some insiders make much greater profits from their limit orders by not paying for immediacy of execution. Prices rise by 172 basis points following insiders' limit purchases compared to 12 basis points for market purchases. This finding suggests that characterizing all market orders as information-motivated trades and all limit orders as liquidity-motivated trades is not appropriate for all informed traders. Some corporate insiders with monopolistic access to long-lived information do not appear to be in any hurry to execute their trades. For this reason, limit orders appear to be the better choice for them. One implication of our findings is that a heuristic association between trade characteristics (such as urgency of trade, trade size, firm size) and the presence of informed trading is likely to be weak.

We also find evidence consistent with the expectation that market professionals discover and piggy-back on insiders' transactions. After controlling for publicly observable trade characteristics, initial stock price reaction is greater for top executives' and officers' trades than it is for large shareholders' trades even though the specifics of insider trading are not made public for another 2-40 days. Upon arrival, insiders' trades lead to significant increases in trading intensity lasting for more than five minutes for insiders' purchases. Insiders' trades also reverse the order imbalances that were present earlier in the day. Prior to insiders' purchases, order imbalances favored sales. Following insiders' purchases, impatient traders send buy orders. There is a similar, though weaker, effect for insiders' sales as well. Since only market professionals are likely to be aware of the arrival of insiders' trades, this evidence is consistent with the expectation that market professionals piggy-back on insider trading.

To ensure that our results are not caused by insiders themselves, we focus on isolated insider trading activity. For this purpose, we examine all the results for a subsample of 117,179 trades that do not have other insider trading around a three-day window of insiders' trades. Our results remain similar for isolated insider trades. Overall, our evidence indicates that the findings are caused by the market's reaction to insider trading, not by insiders themselves.

Finally, our evidence suggests that market professionals do not lose much to insiders as they discover the presence of insiders immediately and act on this information. Market professionals take advantage of their knowledge by first changing the price on insiders and second by piggybacking on insider trading. This evidence suggests that cost of insider trading is likely to fall on uninformed liquidity traders instead of market professionals.

\section{Appendix: Matching Efficiency and Test for Potential Biases}

We list the numbers and percentages of original reported trades that pass each of the seven filters conditional on trade size in Table A1. The last column reports the results for the total sample. The original insider trade data contains a total of 1,422,644 reported trades. We lose approximately $7 \%$ of the original trades to Filter 1 (valid identification), $3 \%$ to Filter 2 (valid market value) and Filter 3 (valid volume of trade), and 27\% to Filter 4 (insider trade with unique size, volume, and date for a given firm), or an exact total of $36.45 \%$ to the first four filters. Overall, $63.55 \%$ of the original data pass the first four filters, which required at least one price 


\section{Table A1. Summary Statistics on Matching Efficiencies}

This table presents percentages and numbers of insider trades passing each of the seven filters by trade size. The seven filters are defined as follows. Filter 1: the insider trade has a matching ticker symbol in the ISSM/ Trade and Quote (TAQ) databases. Filter 2: the firm has a valid market value for the year of the insider trade. Filter 3: the insider trade has a valid trade size. Filter 4: insider trades on the same date with same size and price at the same firm are eliminated. Filter 5: the insider trade has a unique price volume match in the ISSM/TAQ databases. The price of the insider trade is within a half cent of eighths so the trade has a valid price to be matched with before June 1997. The insider trade is required to be within half a cent of sixteenths after June 1997 until the specific start date of the Decimalization period for the firm. Exact price matching is required with the Decimalization period. Filter 6: the insider trade passes filter 5, and the uniquely matched trade in the ISSM/TAQ is executed on the listing exchange of the stock. Filter 7: the insider trade passes filter 6 , and the uniquely matched trade in the ISSM/TAQ is executed within the normal 9:30 a.m.-4 p.m. trading hours.

\begin{tabular}{lcccccc}
\hline \hline & \multicolumn{5}{c}{ Trade Size within } \\
\cline { 2 - 7 } & $\mathbf{1 0 0}$ & $\mathbf{1 0 0 0}$, & $\mathbf{1 1 , 0 0 0 ,}$ & $\mathbf{1 0 , 0 0 0 ,}$ & $\mathbf{2 5 0 , 0 0 0}$ & Total \\
& $\mathbf{5 0 0}$ & $\mathbf{1 , 0 0 0}$ & $\mathbf{1 0 , 0 0 0 )}$ & $\mathbf{5 0 , 0 0 0 )}$ & & \\
\hline Original sample & $100.0 \%$ & $100.0 \%$ & $100.0 \%$ & $100.0 \%$ & $100.0 \%$ & $100.0 \%$ \\
& 170,061 & 123,121 & 700,189 & 319,600 & 109,673 & $1,422,644$ \\
Passing Filter 1 & $93.63 \%$ & $94.02 \%$ & $93.98 \%$ & $93.37 \%$ & $89.86 \%$ & $93.49 \%$ \\
& 159,221 & 115,757 & 658,048 & 298,414 & 98,552 & $1,329,992$ \\
Passing Filter 2 & $93.01 \%$ & $93.33 \%$ & $93.38 \%$ & $92.64 \%$ & $88.25 \%$ & $92.77 \%$ \\
& 158,166 & 114,905 & 653,850 & 296,071 & 96,781 & $1,319,773$ \\
Passing Filter 3 & $88.10 \%$ & $89.20 \%$ & $91.31 \%$ & $91.16 \%$ & $86.84 \%$ & $90.37 \%$ \\
& 149,826 & 109,824 & 639,367 & 291,343 & 95,238 & $1,285,598$ \\
Passing Filter 4 & $55.70 \%$ & $63.58 \%$ & $67.16 \%$ & $63.78 \%$ & $51.94 \%$ & $63.55 \%$ \\
& 94,719 & 78,283 & 470,239 & 203,838 & 56,968 & 904,047 \\
Passing Filter 5 & $14.34 \%$ & $17.27 \%$ & $16.64 \%$ & $11.99 \%$ & $6.05 \%$ & $14.56 \%$ \\
& 24,390 & 21,257 & 116,537 & 38,314 & 6,634 & 207,132 \\
Passing Filter 6 & $13.31 \%$ & $16.24 \%$ & $15.58 \%$ & $10.88 \%$ & $4.93 \%$ & $13.49 \%$ \\
& 22,630 & 19,989 & 109,114 & 34,761 & 5,409 & 191,903 \\
Passing Filter 7 & $12.35 \%$ & $15.28 \%$ & $14.60 \%$ & $9.84 \%$ & $3.89 \%$ & $12.49 \%$ \\
(intraday sample) & 20,995 & 18,811 & 102,212 & 31,457 & 4,270 & 177,745 \\
\hline \hline
\end{tabular}

volume match between each reported insider trade and those in the ISSM and TAQ databases and $36.45 \%$ of the original reported trades are not matched in the background trading.

The passing percentages also depend on trade size. Table A1 demonstrates that $56 \%$ of the trades between 100 and 500 shares, $64 \%$ of the trades between 500 and 1,000 shares, $67 \%$ of the trades between 1,000 and 10,000 shares, and $64 \%$ of the trades between 10,000 and 50,000 shares pass Filter 4, thereby containing a unique firm date and price volume trade for which a background trade match may exist. Cornell and Sirri (1992) report matching 78 of 124 trades, obtaining a success ratio of $63 \%$, which is comparable to our matching success for nonblock trades. Once we move to large block trades of more than 50,000 shares, our matching potential falls to $52 \%$.

When we apply Filter 5 (unique price and unique volume match), we lose another $49 \%$ of the original reported trades. Hence, our biggest loss occurs not because we cannot identify the insider trade at all, but because we identify multiple matches between the insider trade and background trading placed by noninsiders. There just happens to be additional trades placed by noninsiders with the same price and trade volume as the insider trade in the same firm on the same day. 
Since we do not know which of these matching trades is initiated by the insider, we eliminate that particular trade. Filters 6 and 7 (listed exchange and regular trading hours) further eliminate about $2 \%$ of the data. The final intraday sample contains $12.5 \%$ of the trades reported in the original data or $20 \%$ of the original data for which background trades could be matched. ${ }^{15}$

It is important to understand why we are not able to identify many of the "reported" insider transactions in the background trading at all (not passing Filters 1-4). First and foremost, after 1991, private sales and purchases are given the same codes ( $\mathrm{S}$ and $\mathrm{P}$ ) as open market sales and purchases. Private transactions refer to trades done directly with other third parties or usually with the firm itself. Since these trades never go through the exchanges, it is not possible to match these trades in the transactions database. During 1990, private transactions constitute about $9 \%$ of the combined sample. Moreover, private transactions involve a much higher volume of shares than open market transactions. For trades involving 50,000 or greater shares, private transactions rise to about $35 \%$ of the total sample. Consequently, more than $70 \%$ of the missing large trades are likely due to the coding of private transactions.

A second reason we cannot match some large trades is that some insiders may simply break up all large trades, whether due to information or liquidity, and report the daily aggregate as if that was a single trade. SEC rules allow insiders to aggregate separate orders executed within the same trading day for reporting purposes. Insiders are generally not allowed to aggregate trades executed across different days; nevertheless, they occasionally report the sum of trades across multiple days. Third, even if insiders submit a single order, brokers can break it up in order to match parts of the order against available liquidity on the other side. If the order is especially large, brokers are almost sure to break it up for execution. Additionally, insiders themselves may break up their large information-related orders for strategic reasons in order to hide the information content of their large trades. For reporting purposes, they simply report the totals for the day. In this case, we also will have trouble matching large orders.

Our empirical tests can help distinguish between the above listed four different causes of nonmatching transactions. Information content of private transactions is similar to that of open market transactions. Consequently, under the first scenario, there should be no difference in information content of matched and nonmatched transactions. If insiders break up some of their large orders randomly or brokers break up some of the large orders arbitrarily in order to execute them more efficiently, then nonmatching orders should have similar information content as the matching orders. This is because under all three scenarios, the break-up decision is independent of the information content of the trade. Within the matched sample, large trades should still contain more information than small trades. However, if insiders break up only large informationrelated trades for strategic reasons, then nonmatched orders should contain more information than matched orders. Within the matched and nonmatched samples, there should be no positive relationship between trade volume and information content.

We first test for the differences in the information content of matched and nonmatched samples. To begin, we partition the original insider trade sample into two nonoverlapping subsamples: Group 1 represents the matched insider trades that have passed all seven filters, and Group 2 represents the nonmatched insider trades that have failed any one of the seven filters. For each group, we examine the price behavior from 30 days before to 30 days after the insider trading day

\footnotetext{
${ }^{15} \mathrm{We}$ also examine the passing percentages by the identity of insiders, firm size, and sales versus purchases (not shown here). We were more successful in matching top executives' $(19.7 \%)$ and officers' trades (20.5\%) than matching large shareholders' trades $(16.1 \%)$. Note that the large shareholders' trades are typically larger than other insiders' trades (the percentages correspond to the ratios of matched and identified insider trades to the insider trades after Filter 5). We were about equally successful in matching purchases (20.3\%) and sales (19.3\%) and more successful in smaller firms (19.8\% in firm size Group 1 and $21.8 \%$ in firm size Group 2) than in large firms (16.5\% in firm size Group 4).
} 
Figure A1. Abnormal Stock Price Behavior 30 Days before to 30 Days after Insiders' Trades for Matched and Nonmatched Trades

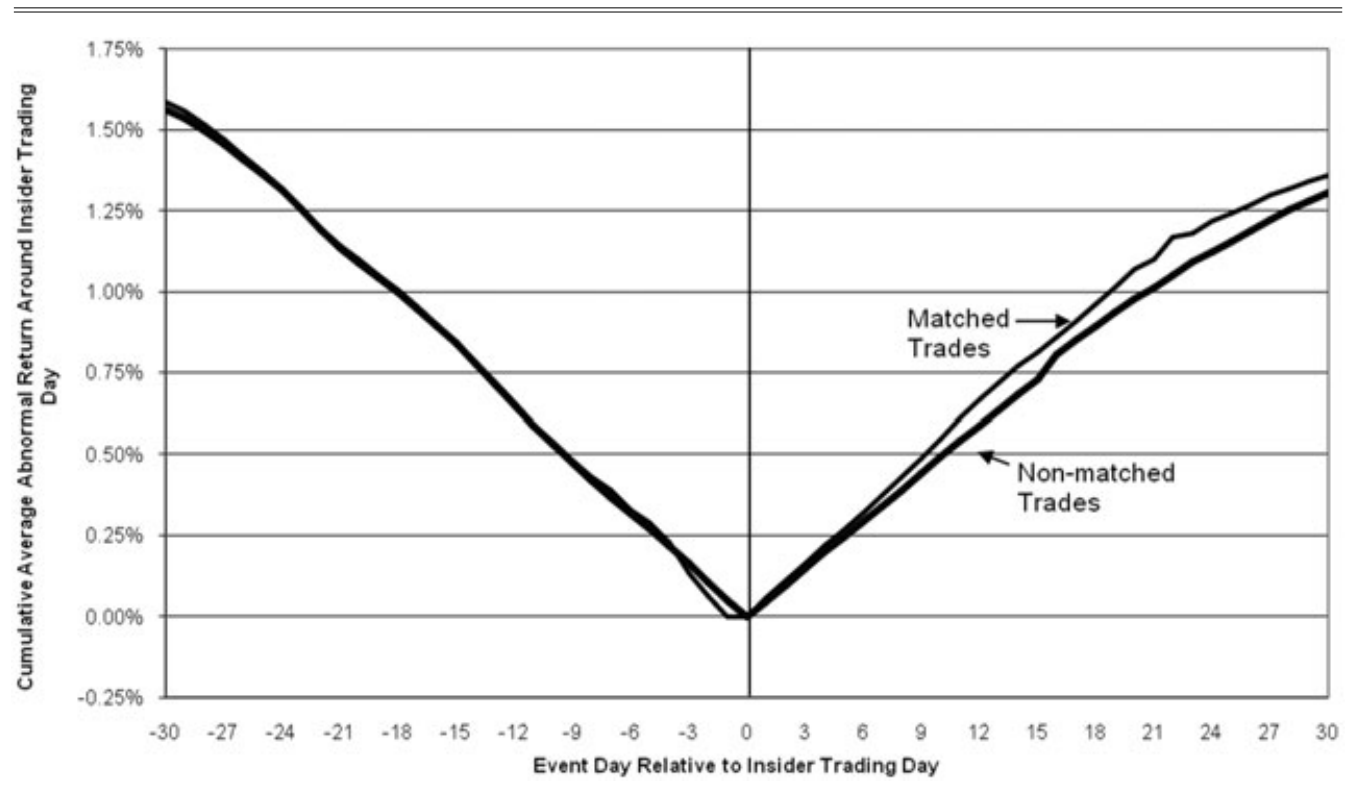

denoted as Day 0. We use the standard event study method and compute the abnormal returns as the difference between the daily return to each firm minus the daily return to the equally weighted market index. We then compute the CAARs by averaging and then summing the abnormal returns. These returns are computed as follows:

$$
\begin{aligned}
A R_{d, i} & =\left(\ln P_{d, i}-\ln P_{d-1, i}\right)-\left(\ln M_{d}-\ln M_{d-1}\right), \\
A A R_{d} & =\frac{1}{N_{d}} \sum_{i=1}^{N_{d}} A R_{d, i}, \\
C A A R_{d} & =\sum_{\tau=-30}^{d} A A R_{d, i},
\end{aligned}
$$

where $d=(-30, \ldots, 0, \ldots, 30), P_{d, i}$ refers to the closing price of the stock of the $i$ th insider trade on day $d, M_{d}$ refers to the level of equally weighted market index at the end of day $d$, and $N_{d}$ is the number of returns available for day $d$. For insider sales, we multiply the abnormal returns, $A R_{d, i}$, by -1 . Finally, we normalize the CAARs by setting the CAAR on the insider trading day to zero.

These CAARs from 30 days before to 30 days after the insider trading day are plotted in Figure A1. They are very similar for both groups (matched and nonmatched trades). In general, the CAARs have the same shape. They decline prior to the insider trading day and rise thereafter. Figure A1 indicates that the price patterns around the two groups of insider trades are very close and are almost indistinguishable. 
Formal statistical tests confirm that the differences in CAARs of the two groups never attain statistical significance at any time horizon. For example, the CAAR from the insider trading day to Day 30 is about $1.36 \%$ for matched insider trades and about $1.31 \%$ for nonmatched trades. Both CAARs are highly statistically significant with $p$-values of 0.00 . However, their difference is insignificant from zero with a $p$-value of 0.76 .

To further distinguish between the four different causes of nonmatching trades, we also test the differences of the CAARs of the matched and nonmatched subsamples by three trade size groups: 1) 100-999 shares, 2) 1,000-9,999 shares, and 3) 10,000 shares or greater. We find that the information content of insiders' trades increases with trade size in both groups. This finding constitutes evidence against the strategic break-up hypothesis, which predicts a nonpositive relationship between volume and information content for both groups. The fact that information content also increases with volume for the matched sample further suggests that large matched trades do come from insiders rather than uninformed outsiders due to subtle mismatches. Finally, our evidence confirms that for a given trade size, the abnormal returns for matched and nonmatched trades are very similar. The differences in CAARs do not attain statistical significance for any holding period.

Overall, our evidence indicates that the information content of matched insider trades does not appear to be different from that of the nonmatched sample. This finding is consistent with the first three scenarios and inconsistent with the strategic break-up hypothesis. Under the strategic break-up hypothesis, we would have found the information content of the nonmatched trades to be larger than that of the matched trades. We would have also expected a nonpositive correlation between trade size and information content in both groups. ${ }^{16}$

\section{References}

Admati, A.R. and P. Pfleiderer, 1988, “A Theory of Intraday Patterns: Volume and Price Variability,” Review of Financial Studies 1, 3-40.

Affleck-Graves, J., S.P. Hegde, and R.E. Miller, 1994, "Trading Mechanisms and the Components of the Bid-Ask Spread," Journal of Finance 49, 1471-1488.

Andersen, T.G., T. Bollerslev, F.X. Diebold, and H. Ebens, 2001, "The Distribution of Stock Return Volatility," Journal of Financial Economics 61, 43-76.

Bagehot, W., 1971, “The Only Game in Town," Financial Analysts Journal 27, 12-24.

Bamber L., O. Barron, and T. Stober, 1997 "Trading Volume and Different Aspects of Disagreements Coincident with Earnings Announcements," Accounting Review 72, 575-597.

Bamber L., O. Barron, and T. Stober, 1999 "Differential Interpretations and Trading Volume," Journal of Financial and Quantitative Analysis 34, 369-386.

Barclay, M.J., R.H. Litzenberger, and J.B. Warner, 1990, "Private Information, Trading Volume and Stock Return Variances," Review of Financial Studies 3, 233-253.

Barclay, M.J. and J.B. Warner, 1993, “Stealth Trading and Volatility,” Journal of Financial Economics 34, 281-306.

\footnotetext{
${ }^{16}$ Another possible bias may be that insiders break up their trades and report the average price and volume, which happen to be the same as a valid price and volume traded by another market participant in the same day. In this case, what shows up in the matched sample is not the insider trade but another trade by a noninsider. To guard against this subtle bias, we also replicate our tests using only the predecimalization period during which it is quite unlikely that an average price would be the same as a valid price. Our results remain unchanged using only the predecimalization period.
} 
Bettis, J.C., J.L. Coles, and M.L. Lemmon, 2000, "Corporate Policies Restricting Trading by Insiders," Journal of Financial Economics 57, 191-220.

Chakravarty, S., 2001, "Stealth Trading: Which Traders Move Stock Prices?" Journal of Financial Economics 61, 287-307.

Chakravarty, S. and J.J. McConnell, 1997, “An Analysis of Prices, Bid/Ask Spreads, and Bid and Ask Depths Surrounding Ivan Boesky's Illegal Trading in Carnation's Stock," Financial Management 26, 18-34.

Chakravarty, S. and J.J. McConnell, 1999, "Does Insider Trading Really Move the Stock Prices?” Journal of Financial and Quantitative Analysis 34, 191-209.

Chan, L. and J. Lakonishok, 1993, "Institutional Trades and Intraday Stock Price Behavior," Journal of Financial Economics 33, 173-199.

Chan, L. and J. Lakonishok, 1995, "The Behavior of Stock Prices Around Institutional Trades," Journal of Finance 50, 1147-1174.

Chiang, R. and P.C. Venkatesh, 1988, "Insider Holdings and Perceptions of Information Asymmetry: A Note," Journal of Finance 43, 1041-1048.

Chordia, T., R. Roll, and A. Subrahmanyam, 2005, "Evidence on the Speed of Convergence to Market Efficiency," Journal of Financial Economics 76, 271-292.

Chung, K. and C. Charoenwong, 1998, "Insider Trading and Bid-Ask Spread,” Financial Review 33, 1-20.

Cornell, B. and E.R. Sirri, 1992, "The Reaction of Investors and Stock Prices to Insider Trading," Journal of Finance 47, 1031-1059.

Easley, D., N. Kiefer, M. O'Hara, and J. Paperman, 1996, “Liquidity, Information, and Infrequently Traded Stocks," Journal of Finance 51, 1405-1436.

Easley, D. and M. O’Hara, 1987, "Prices, Trade Size, and Information in Security Markets," Journal of Financial Economics 19, 69-90.

Eckbo, B.E. and D.C. Smith, 1998, "The Conditional Performance of Insider Trades," Journal of Finance $53,467-498$.

Fama, E. and J. MacBeth, 1973, “Risk, Return, and Equilibrium: Empirical Tests," Journal of Political Economy 81, 607-636.

Finnerty, J.E., 1976, “Insiders and Market Efficiency,” Journal of Finance 31, 1141-1148.

Fishe, R.P.H. and M.A. Robe, 2004, “The Impact of Illegal Insider Trading in Dealer and Specialist Markets: Evidence from a Natural Experiment," Journal of Financial Economics 71, 461-488.

Fleming M. and E. Remolona, 1999, "Price Formation and Liquidity in the US Treasury Market: The Response to Public Information," Journal of Finance 54, 1901-1915.

Foster, D. and S. Viswanathan, 1994, "Strategic Trading with Asymmetrically Informed Traders and LongLived Information," Journal of Financial and Quantitative Analysis 29, 499-518.

French, K.R. and R. Roll, 1986, "Stock Return Variances: The Arrival Information and Reaction of Traders," Journal of Financial Economics 17, 5-26.

Garfinkel, J.A., K. Kahle, and K. Shastri, 2007, "Information, Incentive Alignment, and Company Loan Financing of Insider Trades," Financial Management 36, 67-87.

Garfinkel, J.A. and M. Nimalendran, 2003, "Market Structure and Trader Anonymity: An Analysis of Insider Trading," Journal of Financial and Quantitative Analysis 38, 591-610. 
Glosten, L.R., 1989, "Insider Trading, Liquidity, and the Role of the Monopolist Specialist," Journal of Business 62, 211-235.

Glosten, L.R. and P. Milgrom, 1985, "Bid, Ask, and Transaction Prices in a Market-Maker Market with Heterogeneously Informed Traders," Journal of Financial Economics 14, 71-100.

Griffiths, M., B.F. Smith, D.A.S. Turnbull, and R.W. White, 2000, "The Costs and Determinants of Order Aggressiveness," Journal of Financial Economics 56, 65-88.

Grossman, S.J., 1976, "On the Efficiency of Competitive Stock Markets Where Trades Have Diverse Information," Journal of Finance 31, 573-585.

Grossman, S.J. and J.E. Stiglitz, 1980, "On the Impossibility of Informationally Efficient Markets,” American Economic Review 70, 393-408.

Harris, L.E. and J. Hasbrouck, 1996, "Market versus Limit Orders: The Super DOT Evidence on Order Submission Strategy," Journal of Financial and Quantitative Analysis 31, 213-231.

Hasbrouck, J., 1991a, "Measuring the Information Content of Stock Trades," Journal of Finance 46, 179-207.

Hasbrouck, J., 1991b, "The Summary of Informativeness of Stock Trades: An Econometric Analysis," Review of Financial Studies 4, 571-595.

Hasbrouck, J. and G. Sofianos, 1993, "The Trades of Market-Makers: An Empirical Analysis of NYSE Specialists," Journal of Finance 48, 1565-1593.

Holthausen, R., R. Leftwich, and D. Mayers, 1987, "The Effect of Large Block Transactions on Security Prices: A Cross-Sectional Analysis," Journal of Financial Economics 19, 237-267.

Holthausen, R., R. Leftwich, and D. Mayers, 1990, "Large-Block Transactions, the Speed of Response, and Temporary and Permanent Stock-Price Effects,” Journal of Financial Economics 26, 71-95.

Hughen, J.C. and C.G. McDonald, 2006, "Does Order Flow Commonality Extend across Trade Sizes and Securities?" Financial Management 35, 107-128.

Jaffe, J.F., 1974, “Special Information and Insider Trading," Journal of Business 47, 410-428.

Jakob, K. and T. Ma, 2005, "Limit Order Adjustment Mechanisms and Ex-Dividend Day Stock Price Behavior," Financial Management 34, 89-101.

Keim, D.B. and A. Madhavan, 1996, "The Upstairs Market for Large-Block Transactions: Analysis and Measurement of Price Effects," Review of Financial Studies 9, 1-36.

Koski, J.L. and R. Michaely, 2000, "Price, Liquidity, and Information Content of Trades," Review of Financial Studies 13, 659-696.

Kraus, A. and H. Stoll, 1972, "Price Impact of Block Trading on the New York Stock Exchange," Journal of Finance 27, 569-588.

Kyle, A., 1985, “Continuous Auctions and Insider Trading,” Econometrica 53, 1315-1335.

Lakonishok, J. and I. Lee, 2001, “Are Insider Trades Informative?” Review of Financial Studies 14, 79-112.

Lee, C. and M. Ready, 1991, "Inferring Trade Direction from Intraday Data," Journal of Finance 46, 733-746.

Lee, C.M.C. and M.J. Ready, 1992, "Earnings News and Small Traders," Journal of Accounting and Economics 15, 265-302.

Lin, J. and J. Howe, 1990, "Insider Trading in the OTC Market," Journal of Finance 45, 1273-1284. 
Meulbroek, L.K., 1992, “An Empirical Analysis of Illegal Insider Trading,” Journal of Finance 47, 16611699.

Nimalendran, M., J.R. Ritter, and D. Zhang, 2007, “Do Today's Trades Affect Tomorrow's IPO Allocations?” Journal of Financial Economics 84, 87-109.

Rozeff, M.S. and M.A. Zaman, 1988, "Market Efficiency and Insider Trading," Journal of Business 61, 25-44.

Seyhun, H.N., 1986, "Insiders' Profits, Costs of Trading, and Market Efficiency," Journal of Financial Economics 16, 189-212.

Seyhun, H.N., 1988, “The Information Content of Aggregate Insider Trading,” Journal of Business 61, 1-24.

Seyhun, H.N., 1998, Investment Intelligence from Insider Trading, Cambridge, MA, MIT Press. 